ANUARIO DE Estudios Medievales

41/2, julio-diciembre de 2011

pp. 819-864

ISSN 0066-5061

\title{
TECNOLOGÍA, LITERATURA TÉCNICA Y DISEÑO DE MÁQUINAS DE GUERRA DURANTE LA BAJA EDAD MEDIA OCCIDENTAL: EL THEXAURUS REGIS FRANCIAE ACQUISITIONIBUS TERRAE SANTAE DE GUIDO DA VIGEVANO $(1335)^{1}$
}

\author{
TECHNOLOGY, TECHNICAL LITERATURE \\ AND THE DESIGN OF WAR MACHINES IN WESTERN EUROPE \\ DURING THE LATE MIDDLE AGES: \\ THE THEXAURUS REGIS FRANCIAE \\ ACQUISITIONIBUS TERRAE SANTAE \\ BY GUIDO DA VIGEVANO (1335)
}

FRANCISCO GARCÍA FITZ

Universidad de Extremadura

\begin{abstract}
Resumen: Aunque durante los primeros siglos de la Edad Media occidental no llegó a olvidarse del todo la tratadística militar clásica, como demuestra la difusión de la obra de Vegecio, y a pesar de que la tecnología y el diseño de máquinas de guerra conoció algunos avances importantes, lo cierto es que habrá que esperar a los siglos XIV y XV para que se produzca el florecimiento de una literatura técnica destinada a difundir nuevos y a veces imaginativos modelos. En este panorama de renovado interés por el diseño y construcción de este tipo de ingenios, el informe presentado en 1335 por Guido da Vigevano a Felipe VI de Francia para la recuperación de Tierra Santa representa un hito fundamental por su originalidad, por la mezcla de pragmatismo y fantasía, y por la influencia de sus propuestas sobre autores posteriores.
\end{abstract}

Palabras clave: tecnología bélica medieval; literatura técnica; máquinas de guerra; Guido da Vigevano.

\begin{abstract}
Although during the early centuries of the Middle Ages in the West the military treatises of Antiquity did not fall completely into oblivion (as can be demonstrated by the diffusion achieved by Vegetius's work), and despite the fact that the technology and design of war engines had undergone some important advances, the fact is that not until the fourteenth and fifteenth centuries did technical literature designed to spread new and sometimes imaginative models flourish. Against this backdrop of renewed interest in the design and construction of this type of machines, the report that Guido da Vigevano presented in 1335 to Philip VI of France for the recovery of the Holy Land represents a milestone because of its originality, the mixture of pragmatism and fantasy, and the influence of Guido's proposals on later authors.
\end{abstract}

Keywords: medieval war technology; technical literature; war machine; Guido da Vigevano.

${ }^{1}$ Este trabajo se ha realizado en el marco del proyecto de investigación HUM2007-63856 del Ministerio de Educación y Ciencia sobre "La transmisión del saber técnico y profesional en la Edad Media". 


\section{SUMARIO}

1. El panorama hasta el siglo XIII.- 1.1. La transmisión del conocimiento clásico.- 1.2. El despertar del siglo XIII.- 2. La eclosión bajomedieval.- 2.1. Otros autores, otras audiencias, una nueva literatura.- 2.2. Hitos significativos.- 3. El Thexaurus regis Franciae acquisitionibus Terrae Santae.- 3.1. El autor y su originalidad.- 3.2. Artefactos y máquinas.- 4. Bibliografía citada.

\section{EL PANORAMA HASTA EL SIGLO XIII}

\subsection{La transmisión del conocimiento clásico}

En el Occidente medieval, la literatura que aborda la tecnología y el diseño de máquinas de guerra presenta, entre los siglos V y XIII, un panorama verdaderamente pobre. Sin duda tanto los ingenios empleados en el campo de batalla como la tratadística militar de esta época fueron deudores de la tradición clásica, pero por lo que respecta a la producción literaria especializada la presencia de obras clásicas resulta raquítica.

Ciertamente, el De Architectura de Vitruvio no fue un texto desconocido durante la Edad Media: estuvo presente en no pocas bibliotecas y el número de sus ejemplares se fue incrementando, hasta el punto de que en la actualidad se conservan más de cincuenta códices manuscritos fechados entre los siglos $\mathrm{X} \mathrm{y} \mathrm{XV}^{2}$. Por tanto, los hombres cultos dispusieron de un texto que prestaba alguna atención a la tecnología militar y al diseño de máquinas bélicas, a las que se dedican los siete últimos capítulos del Libro Décimo en los que se ofrece una minuciosa serie de detalles técnicos referidos a la construcción de diversos ingenios, como catapultas, ballestas, arietes, torres móviles y tortugas. Especialmente interesado se muestra en la indicación de las dimensiones, en las proporciones que debían mantenerse entre sus partes, en la descripción de los diversos componentes, en la naturaleza de algunos de los materiales empleados en su fabricación y en los pasos que debían seguirse para su montaje ${ }^{3}$. Sin embargo, no ha podido señalarse ningún caso de tratado militar o con contenidos relacionados con la tecnología bélica que presente una clara influencia de Vitruvio, al menos con anterioridad al siglo XV.

Caso distinto es el de Vegecio. Su Epitoma rei militaris, escrito a finales del siglo IV, recogía buena parte de la tradición militar anterior. El texto fue muy conocido, estudiado, resumido, copiado y citado durante toda la Edad Media, y a partir del siglo XIII su traducción a diversas lenguas vernáculas incrementó su difusión. Más aún, varias crónicas dan cuenta de su utilización como modelo o inspiración del comportamiento militar de determinados personajes. La prueba más evidente de su amplísima difusión en toda Europa es que se han conservado casi 250 manuscritos medievales de la obra en latín y unos 80 en francés, inglés, italiano, castellano o alemán ${ }^{4}$. Es verdad que los especialistas han puesto en duda que las ideas que aparecen en esta obra tuvieran un impacto real en los comportamientos de los guerreros medievales, pero no puede dudarse de que se convirtió en una verdadera auctoritas, en la más importante de las obras de literatura militar romana heredada por la Edad Media.

\footnotetext{
${ }^{2}$ Sobre la presencia de Vitruvio en la Edad Media véase la introducción de D. Rodríguez Ruiz a la versión española de Vitrubio, Los diez libros, p. 31.

3 Vitrubio, Los diez libros, pp. 381-398.

${ }^{4}$ Véase el estudio introductorio de João Gouveia Monteiro a Vegecio, Compêndio, pp. 108-147.
} 
Cabría suponer, en consecuencia, que a través de este canal la producción libresca del Occidente medieval podría haber recibido al menos una parte del caudal de conocimientos clásicos sobre estas materias.

El autor dedica una docena de capítulos del Libro IV a describir algunos de los ingenios empleados por los romanos -tortuga, ariete, hoz, manteletes, plúteos, músculos, torres móviles, sambuca, exostra, cigoñal, grandes ballestas, dardos incendiarios, fustíbalos, arcoballestas, hondas y lobos-, así como determinadas técnicas de asedio, como la excavación de minas ${ }^{5}$. En la mayoría de los casos ofrece una descripción física de la máquina, algunas noticias sobre su empleo y función, así como indicaciones sobre los materiales que se emplean en su construcción. Excepcionalmente hace alguna referencia a las medidas -caso de los manteletes y las torres-, pero nada menciona sobre su montaje o sobre el proceso de fabricación. En general no es complicado imaginar el tipo de ingenio descrito y su diseño, pero difícilmente podría un constructor o "ingeniero" medieval hacerse una idea, a partir de la lectura del Epitoma, de las técnicas empleadas en su fabricación.

Teniendo en cuenta esto, se comprenden las dificultades que pudieron haber tenido los lectores medievales para entender exactamente el carácter de alguna de las máquinas descritas por Vegecio y, sobre todo, las lagunas que debieron encontrar a la hora de proceder a su diseño a partir únicamente de estas indicaciones. Definitivamente, el Epitoma Rei Militaris no era exactamente un manual técnico para la fabricación de ingenios de guerra.

Otros autores cuyas obras sirvieron como vías de transmisión del conocimiento clásico tampoco resultan particularmente detallistas a la hora de abordar estas materias. Es el caso de San Isidoro: en el Libro XVIII de sus Etimologías, se recogen algunas referencias a determinadas máquinas de guerra, pero la imagen que ofrece de estas no puede ser más genérica: la balista o fundíbalo es descrita como un artefacto que arroja proyectiles (dardos o piedras) y que se tensa mediante correas fabricadas con nervios; del ariete se resalta su función, material y forma de uso; los plúteos son presentados como enrejados entretejidos de cuero sin curtir que sirven para trabajar a cubierto de los enemigos; de los músculos, lo único que subraya es su parecido con el conejo y su empleo en las operaciones de perforación de los muros, si bien no puede adivinarse si el autor habla de un elemento de protección de los atacantes o un instrumento para horadar las murallas 6 .

Hasta donde sabemos, este fue el caudal de información de origen clásico sobre tecnología y diseño de máquinas de guerra que se transmitió al Occidente medieval a través de la literatura. Por supuesto, la transferencia del conocimiento tecnológico no estuvo limitada a la cultura libresca, pues la práctica constructiva quedó en manos de técnicos, artesanos o "ingenieros" que reproducían máquinas similares a las greco-romanas a partir de las experiencias directas aprendidas de sus maestros, ya fuera en el marco de un taller o de un gremio, pero casi siempre mediante una forma de transmisión oral, práctica o directa de maestro a aprendiz, y no a través de una tradición literaria ajena a su proceso de formación.

Bert S. Hall ha advertido sobre el hecho de que la escasez de manuscritos de contenido tecnológico en Occidente hasta el siglo XIV se explica por razones que nada tienen que ver con una supuesta ignorancia o desinterés sobre estas cuestiones, y sí mucho con la naturaleza de las prácticas en los talleres y con las condiciones so-

${ }_{5}^{5}$ M F. Barrio, Edición crítica, Lib. IV, caps. XIV-XXIV. Para la identificación de todos estos ingenios véanse las notas a estos capítulos contenidas en la edición latina y traducción al portugués, citada en nota anterior, Vegecio, Compêndio, a cargo de J. Gouveia. y J.E. Braga, pp. 465-479.

${ }^{6}$ Isidoro de Sevilla, Etimologías, vol. II, Lib. XVIII, pp. 10-11. 
ciales y formación de las gentes de oficio, que eran quienes, en definitiva, construían las máquinas y los depositarios de unos conocimientos técnicos que no pusieron por escrito. Los artesanos difícilmente podían escribir sobre sus artes y oficios porque, en general, eran iletrados. Desde luego, hubo "ingenieros" con suficiente formación para escribir y difundir su obra, pero entonces nos encontramos con una ausencia de interés económico por la difusión y con la política restrictiva de los gremios, nunca excesivamente interesados en que se conocieran hasta los últimos detalles unos procesos de fabricación cuya general propagación podría minar algunos de sus objetivos, como el control y la limitación del acceso al conocimiento. Por otra parte, tampoco parece que el lenguaje ordinario de la época fuera el adecuado para explicar y discutir sobre las realidades complejas de las artes mecánicas. Por lo demás, cuando alguna vez un especialista ponía por escrito determinadas instrucciones para la construcción de una máquina, normalmente su texto no solía dirigirse a un público general, sino a otros especialistas, de ahí el lenguaje críptico que utilizaban y los sobreentendidos que hacen que estos trabajos, rara vez conservados, sean prácticamente ininteligibles para nosotros. Ciertamente los hombres de letras podrían haber recogido por escrito las técnicas de construcción empleadas por los "ingenieros", pero no parece que demostraran demasiado interés por el trabajo artesanal, socialmente considerado como despreciable ${ }^{7}$.

\subsection{El despertar del siglo XIII}

Villard de Honnecourt, autor de una de los primeros textos que incluye una muy breve aproximación a la tecnología y al diseño de máquinas de guerra, responde a este modelo. Su Cuaderno de notas y dibujos, fechado a principios de la década de los 70 del siglo XIII, ofrece una variada gama de propuestas constructivas y viene a demostrar que era esencialmente un "hombre de taller" que, como tantos otros, transmitiría sus conocimientos a través de la enseñanza directa a los aprendices, oficiales y colaboradores a su cargo. Pero también era un hombre ilustrado interesado en difundir sus conocimientos entre una audiencia muy específica: la de aquellos especialistas que pudieran necesitar su ayuda en estas materias. De ahí que la obra haya sido considerada como una pequeña Suma para uso del Maestro de obras, razón por la cual sus explicaciones y dibujos son más técnicos que didácticos, dirigidos a los expertos más que a un público general ${ }^{8}$.

La tecnología militar no es el centro del interés de Villard, pero como ingeniero no pudo resistir la tentación de proponer un diseño original para el ingenio de guerra técnicamente más complejo de su época: el trabuquete de contrapeso. En el momento en que escribe este ingenio no era en absoluto una novedad, pero su propuesta sí lo era respecto al tipo de trabuquete habitual en los siglos XII y XIII: mientras que las máquinas de contrapeso de la época se presentan siempre como unos grandes artefactos que, mediante el contrabalanceo de una verga accionado por el lastre, disparaban grandes bloques de piedra, en el proyecto del célebre arquitecto la verga, igualmente propulsada por la energía cinética del contrapeso, golpearía la base de un gran dardo o flecha, que saldría disparado contra el objetivo previsto.

La descripción que ofrece Villard de Honnecourt es poco clara mientras que el croquis que la acompaña (Fig. 1) únicamente representa la disposición y medidas del zócalo del artefacto -expresadas en el mismo dibujo mediante números romanos-,

\footnotetext{
${ }^{7}$ B.S. Hall, Production et diffusion, pp. 153-154.

8 V. de Honnecourt, Cuaderno, pp. 11-12; R. Bechmann, Villard de Honnecourt, pp. 12 y 57-58; B. Gille, Les ingénieurs, pp. 23-28; J. Gimpel, La revolución industrial, pp. 95-116.
} 
pero no así su alzado, que debía aparecer en otra ilustración que no se ha conservado. La oscuridad del pasaje podría explicarse por el hecho de que el autor se dirigía a un constructor experto, de modo que consideraría innecesario detallar las dimensiones u ofrecer descripciones más realistas. Después de todo, como ha subrayado McGee, Villard podía esperar que los constructores fueran capaces de determinar las dimensiones finales y los arreglos prácticos necesarios ${ }^{9}$.

La reconstrucción realizada por $\mathrm{R}$. Bechmann a partir de la descripción, del dibujo y de las medidas allí recogidas (Fig. 2), permite comprobar que la máquina resultante habría tenido unas dimensiones y un potencial de tiro considerables: un ingenio de 20 metros de alto y otros tantos de largo, dotado de un contrapeso de forma trapezoidal con una capacidad de $18 \mathrm{~m}^{3}$, lo que significa que su peso podría alcanzar las 30 toneladas. Para elevarlo resultaba necesario utilizar un sistema de cuerdas y poleas accionado por varios hombres. Una máquina de estas características podría lanzar un proyectil de $100 \mathrm{~kg}$. - una jabalina de metal de 6 a 8 metros de largo- a más de 400 metros, o bien uno de $250 \mathrm{~kg}$. a más de 160 metros, con una velocidad inicial de $100 \mathrm{~m} / \mathrm{s}$ o de $60 \mathrm{~m} / \mathrm{s}$, según el caso. El disparo resultante podría ser capaz de derribar la puerta de una fortaleza, una empalizada o una parte de un muro, o de hundir un puente levadizo o un barco ${ }^{10}$.

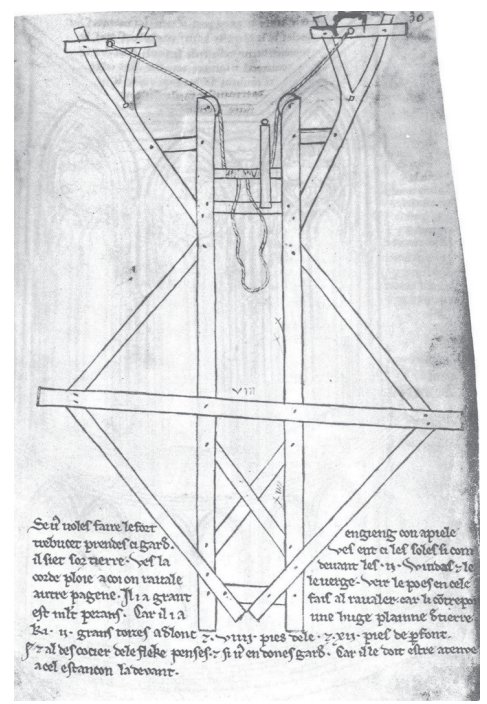

Fig. 1. Trabuquete. Honnecourt.

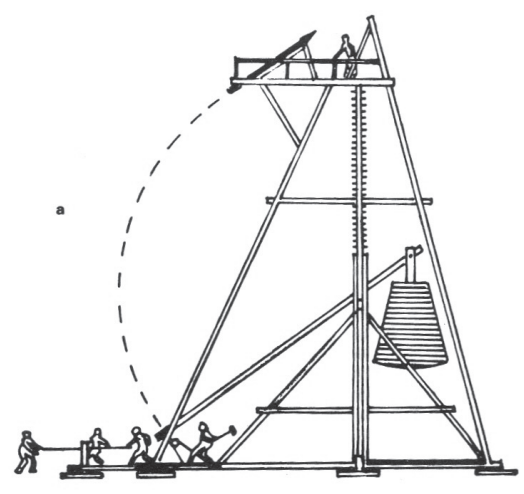

Fig. 2. Reconstrucción del trabuquete de Honnecourt, según Bechmann.

El diseño y construcción de grandes máquinas de lanzamiento de dardos no eran una novedad, pero ni por su tamaño ni por el sistema de propulsión el ingenio de Villard es comparable con sus antecesoras romanas. Por lo demás, en el contexto específicamente medieval, no puede negarse la originalidad y creatividad de su

\footnotetext{
9 D. McGee, The Origins, p. 63.

${ }^{10}$ R. Bechmann, Villard de Honnecourt, pp. 255-272.
} 
propuesta: con su variante el autor daba un paso que iba más allá de la tecnología aplicada en su época. Seguramente, como sostiene Bechmann, las propias medidas, los volúmenes y los pesos implicados en su construcción y uso, así como su coste y la presumible lentitud de su cadencia de tiro, lo harían poco eficiente, sobre todo comparado con los modelos de trabuquete de contrapeso habituales, pero la propuesta de Honnecourt quizás ponga de manifiesto el resurgimiento de una literatura técnica con aportaciones originales sobre el diseño y construcción de máquinas de guerra, una literatura que vendría a demostrar que el camino de la especulación y de la perspectiva tecnológica no había sido abandonado y que la necesidad seguía compeliendo a los hombres a superar sus limitaciones, sus carencias y sus debilidades productivas ${ }^{11}$.

Esta literatura parece resurgir en la segunda mitad del siglo XIII, puesto que la obra de Honnecourt no es un caso completamente aislado. Casi por los mismos años -hacia 1277-1279-Gil de Roma redactaba para su pupilo, el futuro Felipe IV el Hermoso, el De Regimine Principum ${ }^{12}$. Al contrario que el anterior, este trabajo no tiene un carácter técnico ni está destinado a expertos constructores, sino a la educación y formación de un gobernante. Normalmente se entiende que en estas materias Gil de Roma no hace sino reproducir más o menos fielmente a Vegecio, siendo así que su obra habría contribuido de forma decisiva a la difusión del tratadista romano durante la Baja Edad Media ${ }^{13}$. Sin embargo, el análisis de los capítulos dedicados a la descripción de las máquinas de guerra -los comprendidos entre el XVII y el XXII de la Tercera Parte- permite comprobar que el seguimiento que hace de Vegecio, si bien es muy estrecho, se aparta de él al hablar de algunas técnicas particularmente significativas. Así se demuestra, desde luego, en las descripciones que ofrece de las máquinas de lanzamiento de piedras (Lib. III, Tercera Parte, cap. XVIII), que obviamente no encuentran correspondencia en el trabajo del autor tardorromano y que le sirven para ilustrar la tecnología de su propio tiempo.

Baste recordar que Gil de Roma se detiene a explicar la tipología de estos ingenios, distinguiendo cuatro prototipos que, si bien tienen en común el estar todos ellos fundamentados en el mecanismo de la balanza, se diferencian entre sí por el sistema de propulsión. En función de éste, se distinguen dos modelos básicos de ingenios: los que funcionan mediante tracción humana y los que utilizan algún sistema de contrapeso. Los primeros son artefactos en los que el movimiento de la pértiga es accionado por hombres mediante cuerdas. Entre los que emplean el sistema de contrapeso señala a su vez tres tipos de máquinas distintos: el trabuquete, cuyo contrapeso está fijado a la pértiga; la bifa, de contrapeso móvil y unido la pértiga mediante goznes; el tripancio, que combina un contrapeso fijo con uno móvil. El empleo de uno o de otro depende de las circunstancias del asedio: los ingenios de tracción humana lanzaban piedras más pequeñas pero con una mayor cadencia que los de contrapeso; éstos podían arrojar proyectiles de mayor tamaño, con más potencia y a mayor distancia. Por su parte, el trabuquete otorgaba más precisión en la trayectoria, la bifa permitía lanzar a mayor distancia, y el tripancio aunaba ambas virtudes.

Desconocemos si se inspiró en alguna fuente para la presentación de estas máquinas, pero debe indicarse que, si bien no ofrece detalles precisos sobre los procesos de construcción u otras consideraciones técnicas, la tipología que enumera y la descripción de los diseños responden a los modelos empleados en su época y permiten vislumbrar algunos aspectos de la tecnología bélica vigente en la segunda mitad del siglo XIII.

${ }^{11}$ S. Villas, F. Montiel, Historia, p. 144.

${ }_{12}$ Utilizamos la edición de la obra publicada en Roma, 1556.

${ }^{13} \mathrm{~J}$. A. Wisman, L'Epitoma, pp. 27-28. 
Lynn White ha recordado en alguna ocasión que la mentalidad captó por primera vez la invención como proyecto total a finales del siglo XIII'14. Desde luego, los hombres de la Edad Media, por lo que se refiere a la técnica y el diseño de máquinas de guerra, ya habían dado muestras de inventiva mucho antes de esa fecha, pero hasta donde sabemos fue entonces cuando ésta empezó a reflejarse en determinados textos: el panorama de la literatura técnica relacionada con las máquinas de guerra había comenzado a cambiar a lo largo de la segunda mitad de aquel siglo.

\section{LA ECLOSIÓN BAJOMEDIEVAL}

\subsection{Otros autores, otras audiencias, una nueva literatura}

Durante los siglos XIV y XV los escritos se multiplican y comienzan a proliferar obras con propuestas tecnológicas originales cuyos contenidos no se limitan solamente a la descripción de los artefactos, sino que a veces también ofrecen indicaciones más precisas sobre su diseño y fabricación. Esta eclosión, todavía tímida en el siglo XIV, pero floreciente en el XV, parece estar relacionada con un creciente interés por la tecnología entre los sectores cultos, las cortes y las clases dirigentes del Occidente europeo, que culminaría con la verdadera pasión mostrada hacia estas cuestiones ya en el Renacimiento, cuando la figura de Leonardo se convierte en arquetipo de ingeniero y sus obras en modelos de la nueva literatura técnica ${ }^{15}$.

La evolución que se aprecia en los tratados especializados también parece relacionada con un importante cambio sociológico en el mundo de los técnicos, quienes participan de algunos rasgos que no siempre se encuentran en los maestros o artesanos de siglos anteriores: en primer lugar, muchos de ellos son médicos con amplios conocimientos en diversas materias técnicas -astrología, astronomía, matemática- y diestros en el manejo de instrumentos y herramientas, lo que les conduce a la ingeniería en general, y a la militar en particular; en segundo lugar, son hombres de corte, al servicio del poder político, cuyo público ya no es aquél formado por artesanos especialistas -como el de Villard de Honnecourt-, sino cortesanos, monarcas, señores sin conocimientos previos a los que tienen que mostrar sus aportaciones e ideas tecnológicas con cierto didactismo y dejando volar su imaginación. De ahí el interés en hacerlo por escrito, con explicaciones fáciles y dibujos atractivos que fueran comprensibles. Había cambiado el tipo de autor y el tipo de público: la puesta por escrito se hizo ineludible ${ }^{16}$.

Uno de los rasgos más característicos de este nuevo tipo de literatura es su gusto por realizar aportaciones osadas, poco o nada realistas, de difícil construcción o nula eficiencia. En alguna ocasión se les ha calificado como visiones tecnológicas, es decir, sueños tecnológicos que presentan esquemas audaces y fantasiosos que van desde lo improbable al filo de lo imposible, una fórmula que viene a ser el medio empleado por tecnólogos para expresar el aspecto más extravagante y fantástico de su actividad innovadora. Otras veces las propuestas no son exactamente "visiones" o "sueños", sino simples extrapolaciones tecnológicas, ejercicios de imaginación o variantes de temas bien conocidos, que en definitiva sólo van un paso más allá de la técnica conocida, de ahí que se consideren máquinas extrapoladas a partir de la tecnología existente ${ }^{17}$.

${ }^{14}$ L. White, Tecnología, vol. I, p. 94.

${ }^{15}$ B. Gille, Les ingénieurs, passim. Sólo para el siglo XV alemán, se han consignado más de 200 manuscritos sobre esta materia, R. Leng, Ars belli.

${ }^{16}$ B.S. Hall, Production et diffusion, pp. 157-170.

${ }^{17}$ G. Basalla, La evolución de la tecnología, pp. 88-95. 
No deja de ser curiosa la paradoja de que precisamente en una fase histórica en la que la antigua tecnología de guerra se iba progresivamente volviendo obsoleta, en las cortes se despertara y aumentara el interés hacia ellas. Es verdad que aquellas máquinas no desaparecieron, pero lo cierto es que, para entonces, la artillería de pólvora estaba desplazando a las viejas máquinas y, en todo caso, representaba la vanguardia de la tecnología militar. Y es entonces cuando se dispara la inventiva de los técnicos en relación con las máquinas tradicionales ${ }^{18}$. Como quiera que fuese, lo cierto es que el avance de la tecnología militar que se observa durante los dos últimos siglos del Medievo es paralelo al aumento de los tratados técnicos dedicados a la guerra, lo que vendría a probar que las condiciones indispensables para la innovación, definidas como necesidad social, existían y correspondian a las necesidades de una sociedad permanentemente en guerra ${ }^{19}$.

\subsection{Hitos significativos}

Algunos de los rasgos que hemos apuntado como característicos de este nuevo género -por ejemplo una creatividad poco eficiente- ya estaban presentes en el trabuquete diseñado por Villard, pero hay que esperar al siglo XIV para encontrar un ejemplo paradigmático de las nuevas tendencias de esta literatura técnica: nos referimos al Texaurus Regis Franciae, escrito por Guido de Vigevano en 1335. Sin duda es el texto más sobresaliente de toda esta centuria, pero por su singularidad e influencia en los tratados tecnológicos posteriores merece un tratamiento más detallado. Frente a la riqueza de éste, otros textos de este siglo, como el Tractatus de re belica, de Fray Bartolomé Caresi -1340- o el libro Doce de Lo Crestià de Francesc Eiximenis -1385-, no hacen sino repetir básicamente las enseñanzas de Frontino y de Vegecio ${ }^{20}$.

Al margen, pues, de la notable aportación de la obra de Guido da Vigevano, habrá que esperar a principios del siglo XV para que el panorama de la literatura técnica militar se enriquezca definitivamente. No es posible presentar en profundidad todos los tratados aparecidos durante esta centuria, pero al menos cabe hacer una aproximación a los cuatro o cinco textos más significativos para obtener una perspectiva general.

Una de las obras más importantes fue el Bellifortis de Conrad Kyeser, escrito en $1405^{21}$. Su éxito se remonta a la Baja Edad Media, cuando puede constatarse la existencia de un amplio interés por ella entre un público heterogéneo y una notable influencia sobre la literatura técnica posterior: prueba de ello es que sólo del siglo XV se han conservado una veintena de copias manuscritas ${ }^{22}$. Kyeser responde perfectamente al paradigma de "tecnólogo" bajomedieval: un médico de profesión, vinculado a varias cortes europeas a lo largo de su vida -en Alemania, Bohemia y el norte de Italia-, interesando en astrología, pero también en la ingeniería mecánica y en la tecnología militar. Igual que ocurre con la propuesta de Guido da Vigevano, la de Kyeser

${ }^{18}$ M. Popplow, Militärtechnische, p. 252.

19 J. Gimpel, La revolución industrial, p. 181.

${ }^{20}$ L. Villena, Bibliografía, p. 169. En particular para el texto de Eiximenis, véase Dotzen libre, caps. 291-320 [la descripción de las máquinas de asalto en caps. 293-294].

${ }_{21}$ Biblioteca de la Universidad de Göttingen (Cod. Ms. philos. 63), ed. facsímil a cargo de G. Quarg, Conrad Kyeser.

${ }^{22}$ Además de las páginas introductorias de Götz Quarg que acompañan a la edición facsímil ya citada (Düsseldorf, 1967), véase M. Berthelot, Histoire des machines, pp. 289-419; B. Gille, Les ingénieurs, pp. 61-70 y los textos ya citados de B.S. Hall (Production et diffusion) y de M. Popplow (Militärtechnische Bildkataloge). 
se presenta como una respuesta ante un reto militar concreto: una posible reacción armada del Imperio tras la derrota ante los turcos en Nicópolis en 1396.

En consonancia con su perfil profesional, el Bellifortis no es únicamente una obra de contenido militar. De hecho, ha sido considerada como une vaste somme de sciences appliquées que abarca aspectos tan diversos como cuestiones astrológicas, encantamientos mágicos y una variada gama de máquinas de aplicación "civil" Pero Kyeser es esencialmente un "ingeniero" militar y es en este terreno en el que realiza el mayor número de aportaciones.

Destaca la gran variedad de diseños de carros de guerra, desde los grandes triangulares o cuadrangulares fuertemente blindados (Fig. 3) a carretillas de mano más simples y livianas, armadas con hoces, lanzas, picas o bombardas. Especial atención le merecen los ingenios empleados en la guerra de cerco: arietes dotados de traviesas para su manejo, en ocasiones representados en el interior de gatas o construidos sobre ruedas, otras veces ilustrados con diseños fantásticos de tipo antropomórfico; grúas para elevar hombres hasta la altura de las murallas; torres de madera de diversas facciones, a veces con mecanismos de torno para la elevación de la parte superior (Fig. 4), otras dotadas de ruedas y con puentes de asalto, o bien reforzadas con abrigos de madera en la parte posterior para proteger a los hombres encargados de empujarlas hacia la muralla; manteletes y gatas con ruedas para la protección de los hombres; carros terminados en dos puntas -a modo de doble ariete- para forzar puertas; escalas móviles que pivotaban sobre un eje central; varios trabuquetes de contrapeso, cuyas ilustraciones se encuentran entre las más conocidas del Bellifortis (Fig. 5).

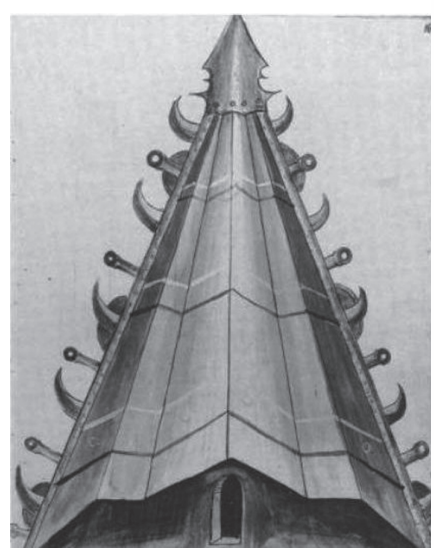

Fig. 3. Carro blindado. Bellifortis.

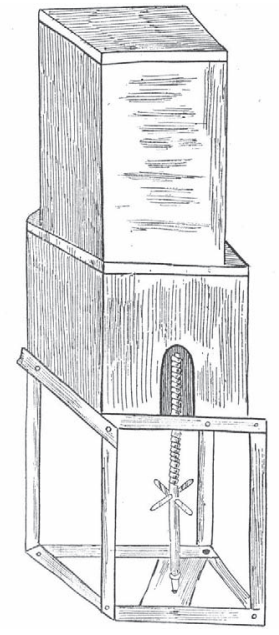

Fig. 4. Torre elevable. Bellifortis.

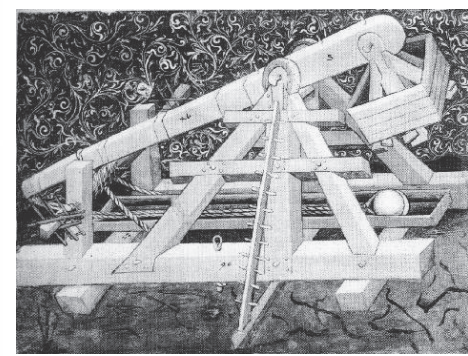

Fig. 5. Trabuquete. Bellifortis.

${ }^{23}$ B.S. Hall, Production et diffusion, p. 166. 
La gama de escalas también es muy variada, desde simples escaleras de madera o cuerda, a complejos modelos articulados o mástiles dotados de escalones laterales y construidos sobre una base rodante que permitía su acercamiento a la pared. Tampoco faltan diversos tipos de ballestas simples, de pie o de torno, algunas diseñadas para lanzar dos dardos a la vez, que son acompañadas de la descripción de flechas con dispositivos incendiarios o con distintos tipos de puntas, así como de aparejos, cinturones y ganchos pensados para tensar las cuerdas de las ballestas.

A un autor del siglo XV interesado en la tecnología militar no podía pasarle inadvertido el desarrollo de las armas de fuego y su potencial. Junto a especificaciones sobre las recetas y el uso del fuego griego y otros mecanismos incendiarios de corte más tradicional -caballos "portafuegos", flechas y vasijas contenedoras de material inflamable, petardos-, aparecen tanto pequeñas bombardas portátiles de poco calibre como otras de mayor tamaño, acompañadas de diseños mucho más imaginativos, donde tres o seis bocas de fuego son montadas sobre un mismo armazón, a veces giratorio para permitir una mayor cadencia de tiro.

Otros artefactos "acuáticos" que, no siendo estrictamente militares, podían llegar a tener una gran utilidad para el desarrollo de las campañas, también son abordados por el autor, y entre ellos nos muestra puentes o pontones para el cruce de ríos o de fosas, diseñados de diversa factura -flotantes, colgantes, plegables, articulados, rodantes...-, barcos impulsados por aspas y equipos para facilitar o asegurar la natación -salvavidas o cinturones inflables- o el buceo - escafandras-.

En fin, la obra también contiene una variada gama de diseños de armas e instrumentos útiles en la guerra: abrojos, arpones, mayales, alabardas, ganchos, mazas, hondas, escudos y manteletes dotados de puntas, zapatos de hierro para andar sobre campos sembrados de abrojos, todos ellos utilizables en diversos contextos bélicos.

El Bellifortis representa un hito en la historia de la literatura técnica del Occidente medieval europeo: recogió una amplísima información sobre la tecnología bélica realmente aplicada no sólo en su época, sino también en siglos anteriores, de modo que en muchas ocasiones no hizo sino ofrecer diseños fidedignos que pudieran servir de modelo para su construcción, si bien sólo en una ocasión se ofrecen las medidas que facilitan la composición de un trabuquete. Desde esta perspectiva la obra podría considerarse como una "antología" o "una selección de máquinas". Este fue, desde luego, el uso que se le dio en las siguientes décadas, cuando otros autores, necesitados de informaciones sobre máquinas de guerra, no dudaron en tomar de ella las ilustraciones que les interesaban para integrarlas en sus propios trabajos. Pero Kyeser no se limitó a recopilar el estado de la tecnología existente o normalmente aplicada a principios del siglo XV, sino que en sus propuestas se incluían también novedades técnicas, como bielas o tornos elevadores. Más aún, algunas de ellas podrían caber dentro de las consideradas visiones tecnológicas, y precisamente la audacia, la creatividad de muchas de sus aportaciones e incluso el recurso a la magia es lo que en buena medida explica su éxito. Claro que en esto el precedente de la obra de Guido da Vigevano es una referencia ineludible. En cualquier caso, la conjugación de una indudable vertiente práctica con una atractiva derivada fantástica le aseguró un puesto de privilegio en la historia de la literatura técnico-militar ${ }^{24}$.

Bastante menos conocida ha sido la obra de otro autor de origen alemán que, en los años finales del siglo XIV y durante el primer cuarto del siglo XV, estuvo al servicio de la corte papal como "ingeniero hidráulico" y desarrolló sus actividades

${ }^{24}$ B. Gille, Les ingénieurs, pp. 69-70; B.S. Hall, Production et diffusion, pp. 165-169; G. Basalla, La evolución de la tecnología, p. 93. 
por diversas ciudades italianas: nos referimos al tratado sobre máquinas y mecánica de Konrad Gruter ${ }^{25}$. Redactado hacia 1423-1424, el manuscrito, procedente de la Biblioteca Apostólica Vaticana -Codex Vat. Lat. 5961-, está dividido en tres grandes partes: las dos primeras están dedicadas a las construcciones hidráulicas y al estudio del movimiento continuo y de los molinos. La tercera, que es la que aquí interesa, es la que se centra en los artefactos militares, De rebus militaribus.

Gruter presta una especial atención a la construcción de puentes, de los que ofrece diversos modelos, unos desmontables y transportables, otros flotantes sobre barriles u odres (Fig. 6). El panorama de los puentes se completa con la descripción de varios sistemas para protegerlos de posibles ataques desde naves o con fuego. Para atravesar corrientes fluviales, pantanos o fosos también propone el diseño de barcos y pontones desmontables. Además, con idea de que pudieran superarse los fosos que solían rodear a las fortalezas, diseña una rampa móvil transportable mediante ruedas (Fig. 7). Relacionado con las actividades acuáticas, también pueden señalarse diversos ingenios de uso personal con los que atravesar corrientes de agua -a modo de salvavidas inflables-o para andar por debajo de ella -escafandras- (Fig. 8).

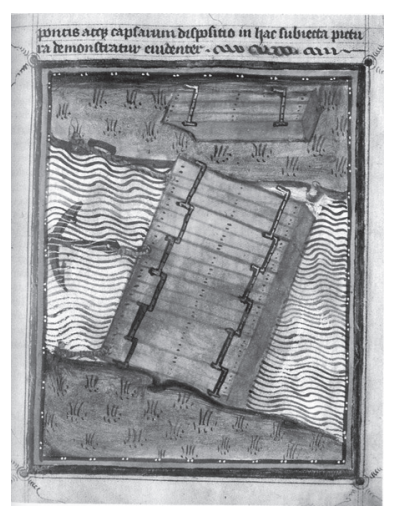

Fig. 6. Puente desmontable. Gruter.

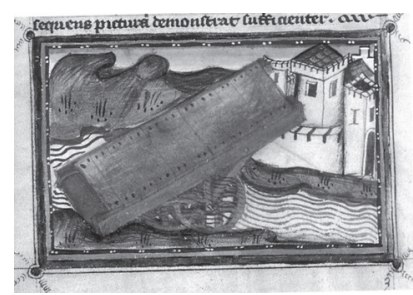

Fig. 7. Rampa de asalto. Gruter.

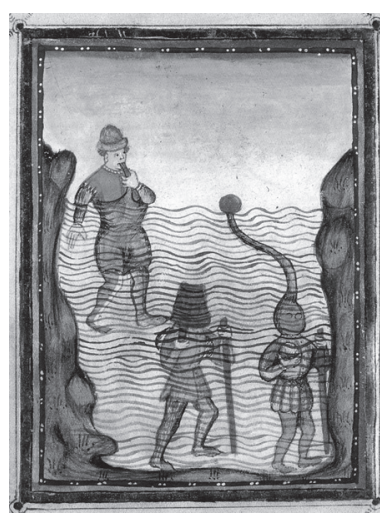

Fig. 8. Salvavidas y escafandras. Gruter.

Igualmente ocupa un lugar importante en sus propuestas la elaboración de un amplio abanico de instrumentos para escalar murallas -escalas de madera, de cuerda y de cuero, zapatos de hierro y manoplas dentadas que permiten ascender a través de postes de madera o sogas-, incluyendo algún sistema de autoelevación a modo de ascensor manual (Figs. 9 y 10). Las tradicionales máquinas de lanzamiento de piedras -trabuquetes de contrapeso- y algunas representaciones de piezas de artillería de pólvora -bombardas de distinta longitud y carros para su transporte-están presentes en la obra, pero en esta categoría de máquinas también se incluye un curioso artefacto para arrojar grandes dardos mediante un sistema de tensión de pértigas de madera (Fig. 11). Por último, cabe destacar un conjunto de aparatos diseñados para romper o arrancar las verjas o los goznes de las puertas (Fig. 12).

\footnotetext{
${ }^{25}$ K. Gruter, De machinis.
} 


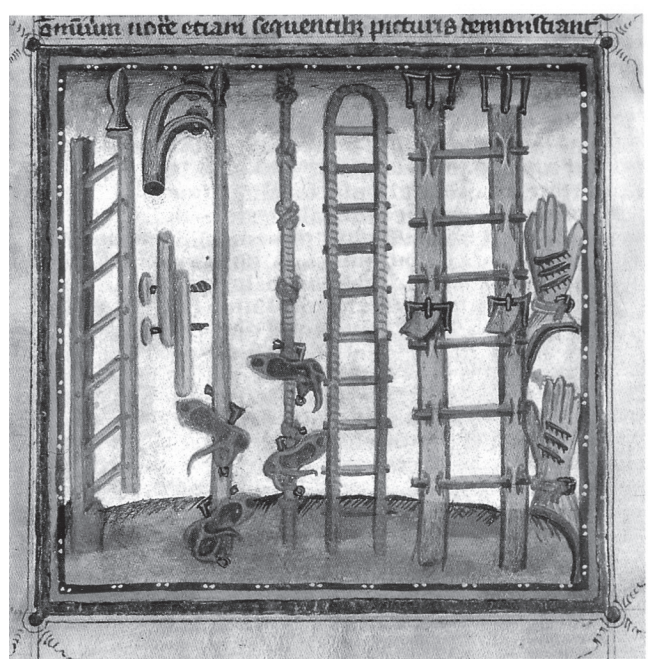

Fig. 9. Escalas. Gruter.

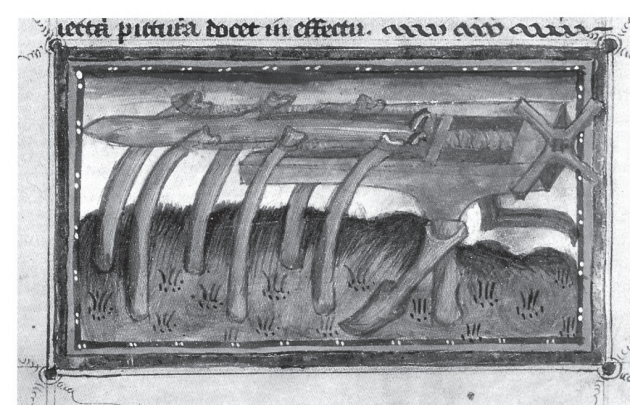

Fig. 11. Lanza dardos. Gruter.

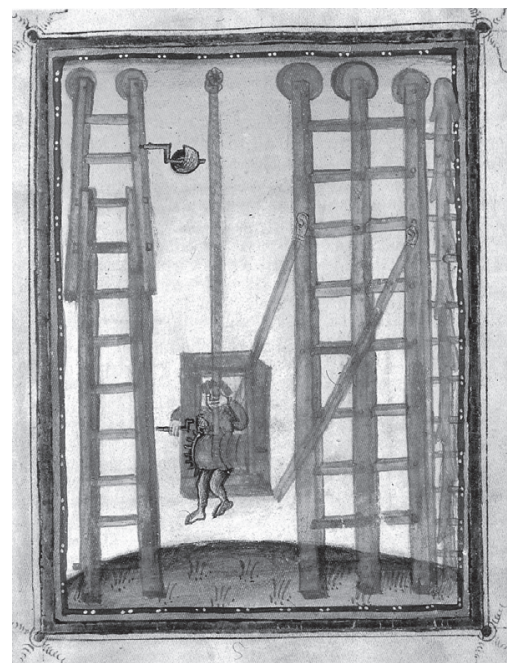

Fig. 10. Escalas. Gruter.

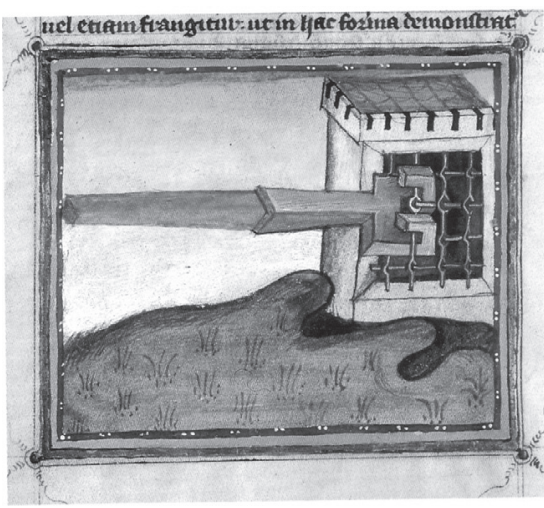

Fig. 12. Palanca. Gruter.

Algunos de estos diseños son antecedentes de los instrumentos que aparecen en muchas de las obras confeccionadas durante las siguientes décadas, pero otros recuerdan a los de autores precedentes, como Guido da Vigevano o Kyeser. No obstante, en comparación con este último, las aportaciones de Gruter destacan por la precisión de sus descripciones y de sus formas de construcción, que resultan muy técnicas y realistas, prescindiendo en todo caso del gusto por la sorpresa y lo maravillo que caracteriza a su antecesor alemán.

Dos de las piezas claves de la literatura técnica militar del siglo XV las encontramos en el Codex Latino 197 de Bayerische Staatsbibliothek de Munich, que tiene como titulo Liber Machinarum et Mechanica. Este códice contiene dos textos distintos: el primero abarca los primeros 48 folios del manuscrito y es el conocido 
como Anónimo de la «Guerra Hussita». El segundo parece ser un cuaderno de notas y dibujos atribuido a Mariano Jacopo "Il Taccola".

El primero es una obra de autor alemán desconocido, tradicionalmente datado en la segunda y tercera década del siglo XV, quizás entre 1421 y 1434, si bien su editor ha propuesto una fecha más tardía, entre 1472 y $1490^{26}$. De lo que no cabe duda es de sus conocimientos tecnológicos en general, y militares en particular. Como ocurría con el Bellifortis, el contenido del Anónimo no es exclusivamente bélico, pero también ahora éste es el más desarrollado, ofreciéndonos un buen elenco de máquinas de guerra, la mayor parte de las cuales tienen un carácter muy realista y presentan ingenios de factura similar a los habitualmente empleados en la guerra, aunque determinadas propuestas sean más creativas. La dependencia de algunos modelos respectos a los diseñados por Kyeser y por Gruter resulta evidente en muchas ocasiones.

Las escalas para el asalto se caracterizan por su sencillez: suelen ser simples escaleras construidas en madera o de cuerda, troncos con tacos a los lados y escalas extensibles o desmontables por secciones, de construcción más sofisticada. Es frecuente que aparezcan dotadas de sistemas de anclaje al muro y al suelo (Fig. 13). Dentro de las técnicas de escalo podría incluirse a la utilizada por una figura que el autor dibuja ascendiendo por un mástil liso, seguramente gracias a algún mecanismo -zapatos dentados o similar-que no se aprecia en el dibujo, pero que podría ser parecido al diseñado por Gruter (Fig. 14).

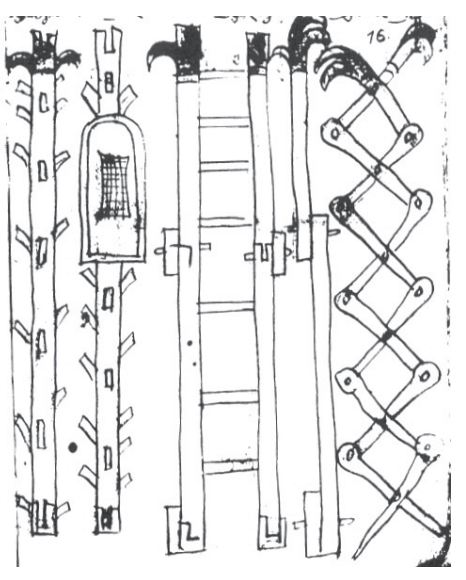

Fig. 13. Escalas. Ms. Guerra Hussita.

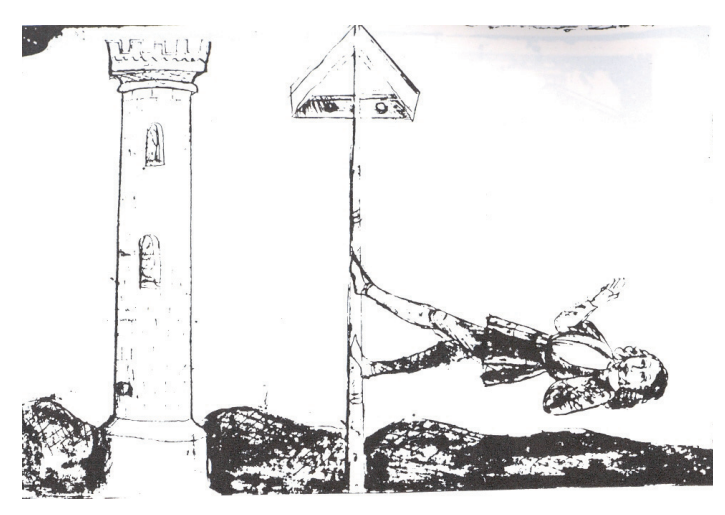

Fig. 14. Escalas. Ms. Guerra Hussita.

Entre los ingenios, llama la atención una torre de observación construida a modo de grúa y diseñada siguiendo los principios de la palanca, con una cesta en un extremo y manejada con tracción humana, que permite la elevación de un hombre por encima de la muralla (Fig. 15). Funciones más complejas de aproximación y asalto cumplen las torres de madera, de las que el autor representa un modelo muy realista

${ }^{26}$ Ed. facsímil en B. S. Hall, The Technological Illustrations, part I. Véase también M. Berthelot, Pour l'histoire des arts, pp. 433-498; B. Gille, Études, pp. 77-86; G. Canestrini, Arte Militare, pp. 31-35; A. Navareño, El armamento, pp. 29-66. 
de varios pisos, dotado de cuatro ruedas y con cuatro pértigas para fijarla al suelo y darle estabilidad (Fig. 16). Similares funciones cumple otra máquina de cerco en la que, sobre una base móvil y artillada, se ha construido una rampa elevable mediante cuerdas, que rememora alguna de las propuestas de Gruter (Fig. 17).

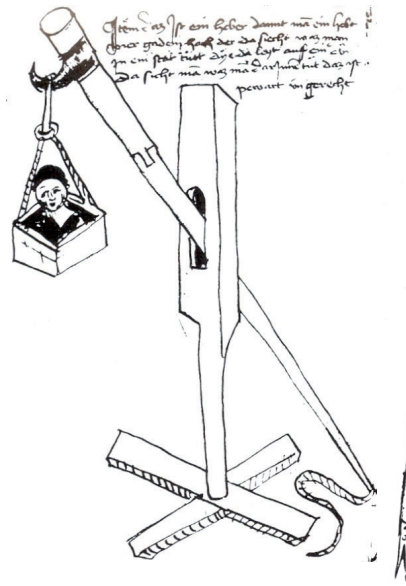

Fig. 15. Grúa. Ms. Guerra Hussita.

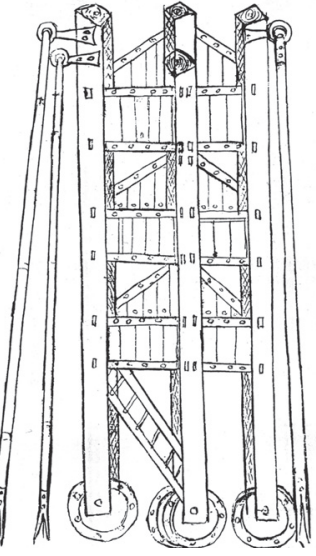

Fig. 16. Torre. Ms. Guerra Hussita.

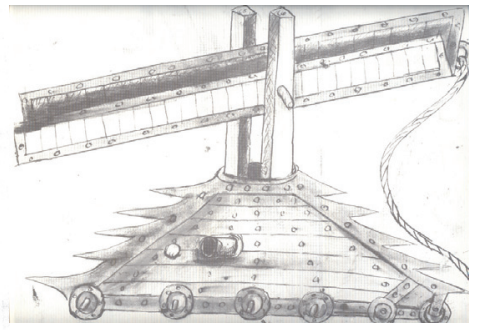

Fig. 17. Rampa de asalto. Ms. Guerra Hussita.

La tipología de ingenios de lanzamiento de piedras y dardos responde a modelos bien conocidos: de una parte, trabuquetes de contrapeso lastrados con pesos fijos y un eje para facilitar la subida del lastre (Fig. 18). De otro, varias ballestas y sus aparejos para tensar las cuerdas, destacando una grande de torno colocada sobre una cureña (Fig. 19).

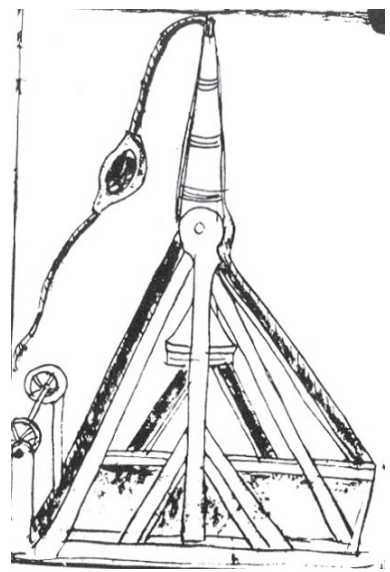

Fig. 18. Trabuquete. $M s$. Guerra Hussita.

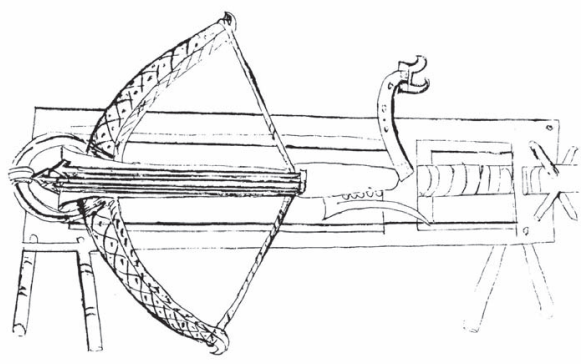

Fig. 19. Ballesta de torno. Ms. Guerra Hussita. 
En relación a los carros de guerra, el Anónimo ofrece sólo un par de ejemplares de vehículos blindados, entre ellos uno que identifica con los utilizados por los hussitas en sus combates en campo abierto y que, de nuevo, resulta muy realista (Fig. 20).

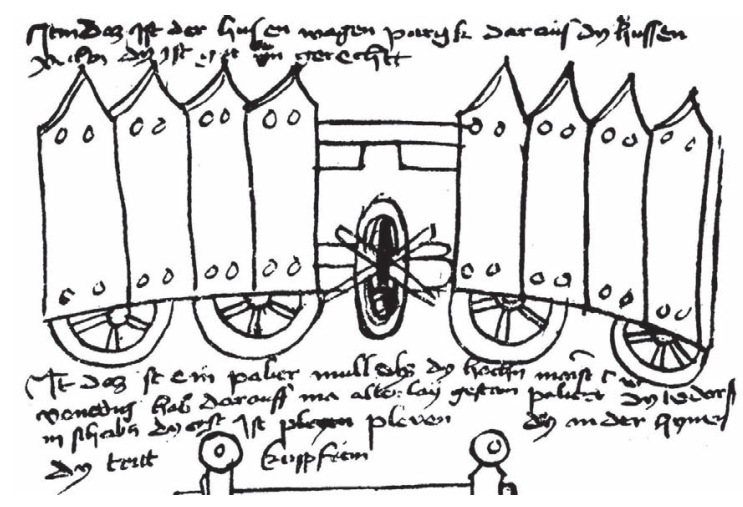

Fig. 20. Carro de combate. Ms. Guerra Hussita.

No pasa desapercibida la importancia del fuego y de las armas incendiarias, cuyo uso aparece representado de varias formas, bien a lomos de un caballo que porta un pebetero ardiendo, bien en un carro que transporta un barril incendiario. Por último, el manuscrito da muestra de la creciente importancia de las armas de pólvora, entre las que se consignan diversas bombardas, algunas sobre cureñas estáticas con sistemas de alza para ajustar el ángulo de tiro; otras con alza y colocadas sobre carretillas para facilitar su movilidad; en ocasiones encastradas en estructuras rodantes fuertemente blindadas, e igualmente se representan en barcos de combate acorazados (Fig. 21). Es destacable una boca de fuego de pequeño calibre situada sobre un eje giratorio dentro de un armatoste blindado (Fig. 22), pero sobre todo la que podríamos denominar "torre de madera artillada", dotada de un elevado número de cañones en cada una de sus tres plantas (Fig. 23).

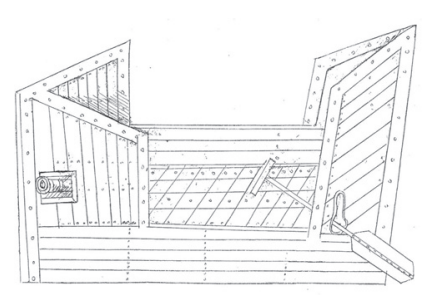

Fig. 21. Barco artillado. Ms. Guerra Hussita.

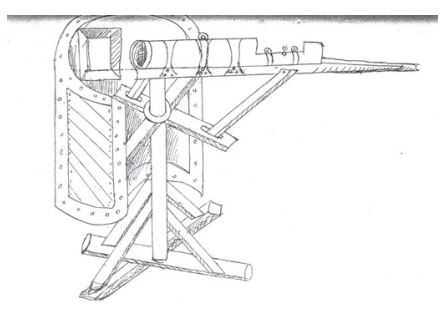

Fig. 22. Bombarda giratoria. Ms. Guerra Hussita.

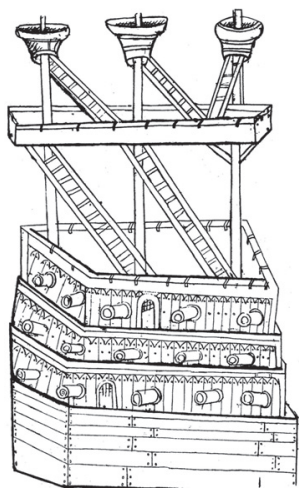

Fig. 23. Torre artillada. Ms. Guerra Hussita. 
Esta nueva artillería planteaba problemas técnicos relacionados no sólo con su fabricación, sino también con su manejabilidad y transporte, un asunto que a los autores parece preocuparle, a tenor de la abundancia de representaciones de aparejos -trípodes y bancos- destinados a elevar las bocas de fuego para colocarlas sobre los carros mediante complejos y variados sistemas de poleas, tornos o tornillos (Fig. 24), así como de carros para su traslado (Fig. 25). Para completar el panorama, el autor recoge igualmente el diseño de un molino para triturar la pólvora.

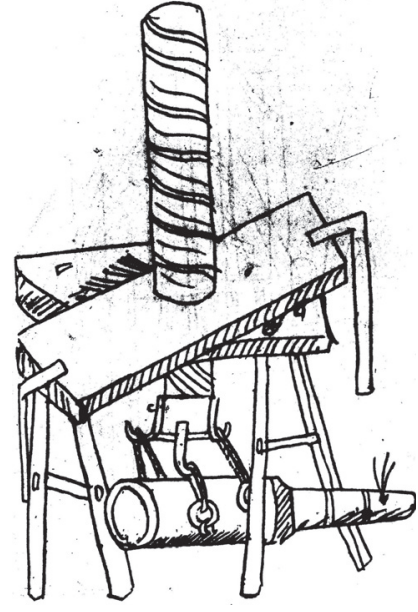

Fig. 24. Banco elevador. $M s$. Guerra Hussita.

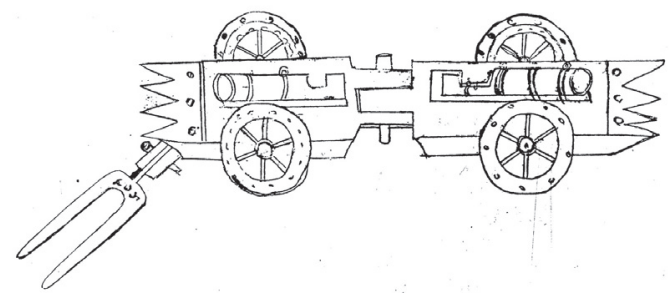

Fig. 25. Carro artillado. Ms. Guerra Hussita.

La importancia del manuscrito de la Guerra Hussita en el contexto de la literatura técnico-militar del siglo XV es reseñable no sólo por el interés que en sí mismo tienen sus representaciones tecnológicas, casi siempre cercanas a la realidad aunque en alguna ocasión sus diseños resulten atrevidos -caso del cañón sobre el armatoste giratorio o la torre artillada-, sino también por sus relaciones con los más importantes textos redactados durante la segunda mitad de dicha centuria y por su posible influencia sobre ellos, en particular por sus conexiones con la obra de Mariano Jacopo "Il Taccola" y con el De Re Militari de Valturio.

Precisamente la segunda parte del Codex Latino 197 de Bayerische Staatsbibliothek de Munich contiene un cuaderno de apuntes atribuido al primero de estos autores, un ingeniero que realizó trabajos de ingeniería civil en Siena en la década de los 30 del siglo XV y que aspiró a ponerse al servicio del emperador alemán, para lo cual posiblemente confeccionó sus manuscritos. Los especialistas sostienen que esta segunda parte del códice de Munich es un borrador o un conjunto de esbozos y de notas realizado por "Il Taccola" entre 1438 y 1441, que serviría de base a otras copias de los años centrales o de la segunda mitad del siglo XV, más elaboradas y completas, de las cuales se han conservado varias, como el De Machinis, libri X de la Biblioteca de San Marcos de Venecia -Códice Manuscrito a. 430, I 295-, el Códice 
Latino 7239 de la Biblioteca Nacional de París, y el Ms. 23172 de la biblioteca del conde Wilczek, en Viena ${ }^{27}$.

Se ha destacado la falta de originalidad del autor, que salvo alguna excepción se habría limitado a dar cuenta del estado de la tecnología de su época, repitiendo fórmulas ya conocidas, pero sin realizar grandes aportaciones personales en ninguna rama de la mecánica o de la física. No obstante, se reconoce que precisamente cette connaissance plus parfaite des posibilites techniques de son époque est sans doute l'un des meilleurs éléments de cet ouvrage ${ }^{28}$. Traducido al ámbito específicamente militar, podría afirmarse que la obra de Mariano Jacopo no es un tratado dedicado a la invención técnica, sino un catálogo ilustrado, con vocación enciclopédica, que recoge tanto las antiguas tradiciones como algunas aportaciones recientes, y que en general prioriza el dibujo y el interés en ofrecer una imagen comprensible de la máquina por encima de las explicaciones técnicas o de la descripción de las partes que la componen o de su montaje $\mathrm{e}^{29}$. El apego del autor a la tradición y a su entorno hace que las máquinas de guerra que diseña sean casi siempre realizables con la tecnología conocida en el siglo XV, pero hay que reconocer que le tienta presentar proyectos imaginativos $y$, por ello, no siempre prácticos.

Aunque, como los autores anteriores, éste tampoco se limita al terreno bélico, desde luego el centro de interés del autor son las máquinas de guerra. El despliegue de representaciones es impresionante, no sólo porque podemos encontrar prácticamente todos los tipos de ingenios bélicos conocidos, sino también por la extraordinaria variedad de diseños. Como acabamos de indicar, "Il Taccola" no suele presentar "visiones" o "sueños" tecnológicos irrealizables, pero sí propuestas "fantasiosas" derivadas de la combinación creativa de varios artefactos bien conocidos y probados.

Buen ejemplo de ello es el amplísimo repertorio de instrumentos para el escalo, que destacan por su complejidad: rara vez representa escalas simples, prefiriendo por el contrario su combinación con otros elementos, tales como plataformas móviles, gatas o mantas para proteger a los asaltantes (Fig. 26). Además, en su catálogo incluye escalas extensibles, desplegables y elevables mediante diversos sistemas de poleas, contrapesos, tracción humana, mecanismos de balanza, tornillo sin fin o ejes tensados, de indudable sofisticación técnica, pero en ocasiones de dudoso pragmatismo o difícil empleo (Figs. 27 y 28).

\footnotetext{
${ }^{27}$ Mariano Jacopo "Il Taccola", De rebus militaribus. A. Navareño publicó un buen número de esbozos de Mariano Jacopo contenidos en el Códice 197 de Munich, mientras que M. Berthelot reprodujo algunos procedentes de este mismo manuscrito y los completó con algunas muestras del Manuscrito 7239 de París. Por su parte, G. Canestrini ha publicado un gran número de dibujos del Códice de Venecia (véase nota supra).

${ }^{28}$ B. Gille, Les ingénieurs, p. 88.

${ }^{29}$ M. Popplow, Militärtechnische, pp. 262-263.
} 

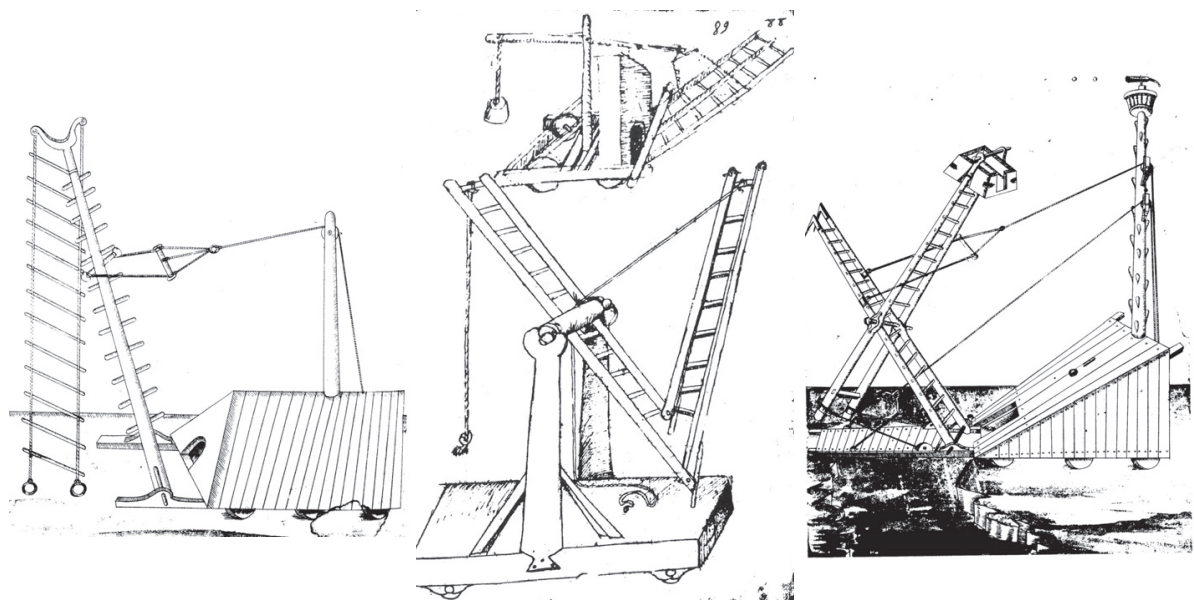

Figs. 26-28. Escalas. "Il Taccola".

Entre las máquinas de asalto se representan distintos tipos de puentes o rampas, alguna de ellas accionada mediante una gran rueda dentada (Fig. 29), así como torres de madera, a veces modelos realistas con ruedas y varios pisos (Fig. 30), otras mucho más ingeniosas en las que dentro del cuerpo principal se embute un segundo cuerpo que se elevaría mediante un sistema de tornillo sin fin (Fig. 31).

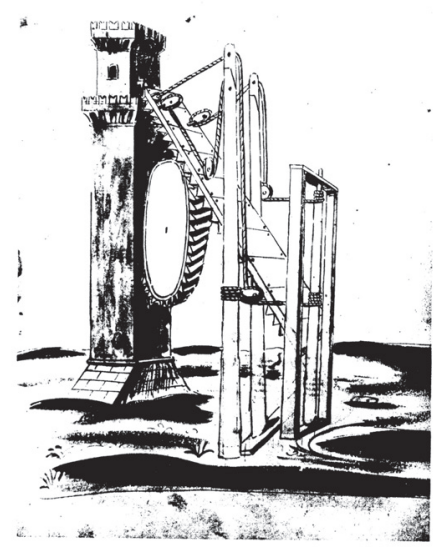

Fig. 29. Puente de asalto. "Il Taccola".

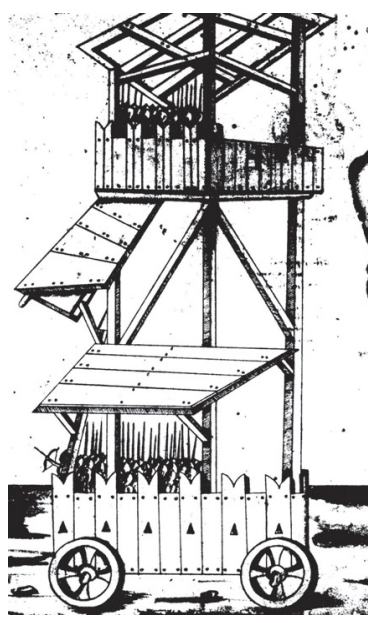

Fig. 30. Torre. "Il Taccola".

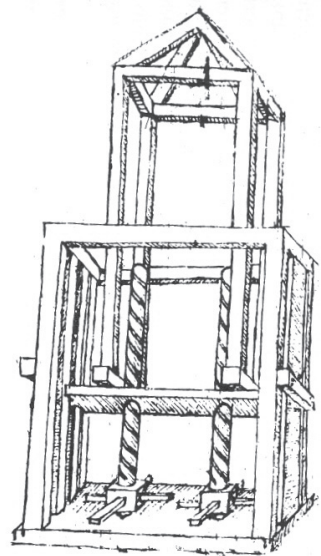

Fig. 31. Torre extensible. "Il Taccola". 
Los ingenios concebidos para la destrucción de puertas y paramentos responden a la tipología clásica: de un lado, los arietes, en cuya representación el autor despliega de nuevo su imaginación asociándolos a otros artefactos que permiten su balanceo -sujetos mediante cuerdas a un entramado de madera-, o su aproximación al muro -dispuestos en casetones o gatas rodantes, en simples carretillas o incluso en la parte inferior de una torre de madera- (Figs. 32-34).
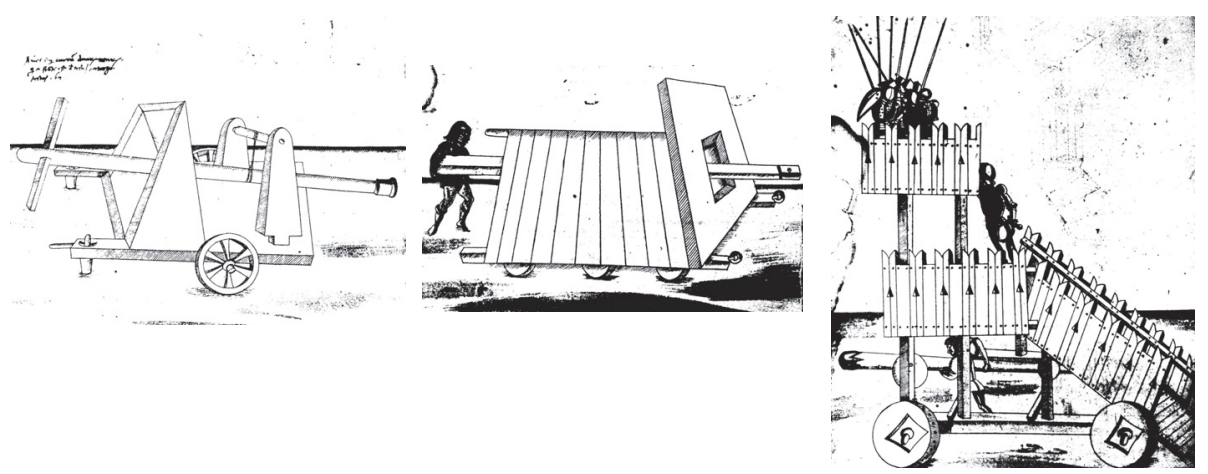

Figs. 32-34. Arietes. "Il Taccola".

De otro, encontramos una amplia representación de los principales modelos de ingenios de lanzamiento de piedras y dardos: varios trabuquetes de contrapeso, algunos lastrados con pesos fijos, otros con pesos móviles construidos a modo de grandes cuencos y tensados gracias a un sistema de poleas o tornos (Figs. 35-36); también da cuenta de alguna catapulta de diseño original, construida básicamente con un único mástil cuya flexión permitiría el lanzamiento de una flecha (Fig. 37).

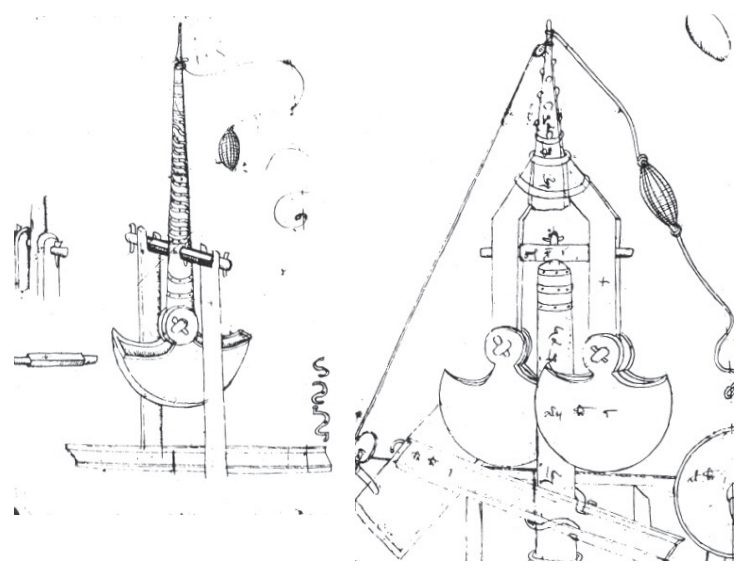

Fig. 35. Trabuquete. "Il Taccola".
Fig. 36. Trabuquete. "Il Taccola".

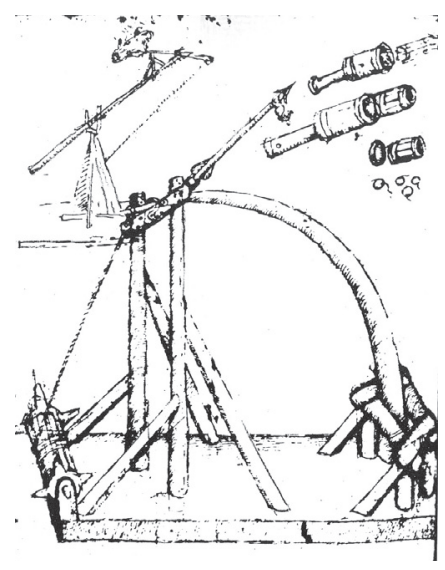

Fig. 37. Catapulta. "Il Taccola". 
Son muy numerosos y variados los ingenios -mantas, gatas, bancos pinjados- diseñados para dispensar protección a los asaltantes o a los hombres que manejaban otros instrumentos -lanzas, arietes, objetos incendiarios, escalas-: son estructuras de madera a modo de escudos o parapetos, si bien las de mayor envergadura son verdaderos casetones. Suelen estar dotadas de ruedas para facilitar su movimiento, lo que hace que las más complejas se asimilen a carros "blindados" (Fig. 38). Algunas de estas máquinas rodantes de aproximación se combinan con una torre de observación y de tiro, lo que da lugar a un artefacto de presencia impresionante (Fig. 39).

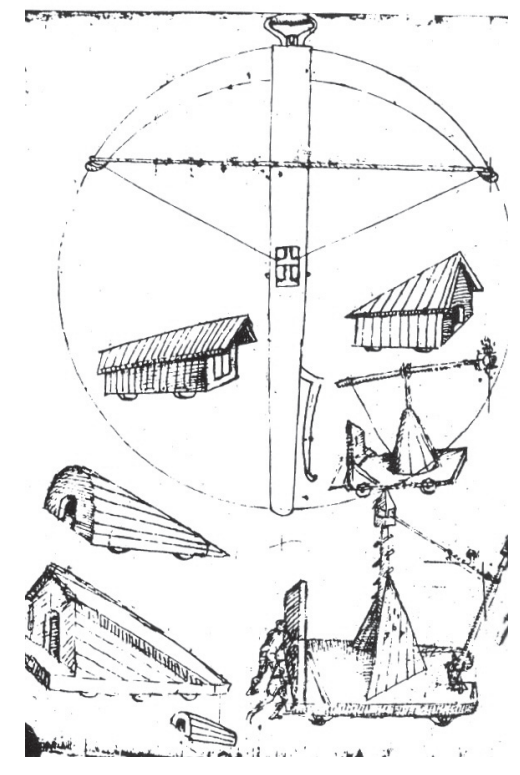

Fig. 38. Mantas y casetones. "Il Taccola".

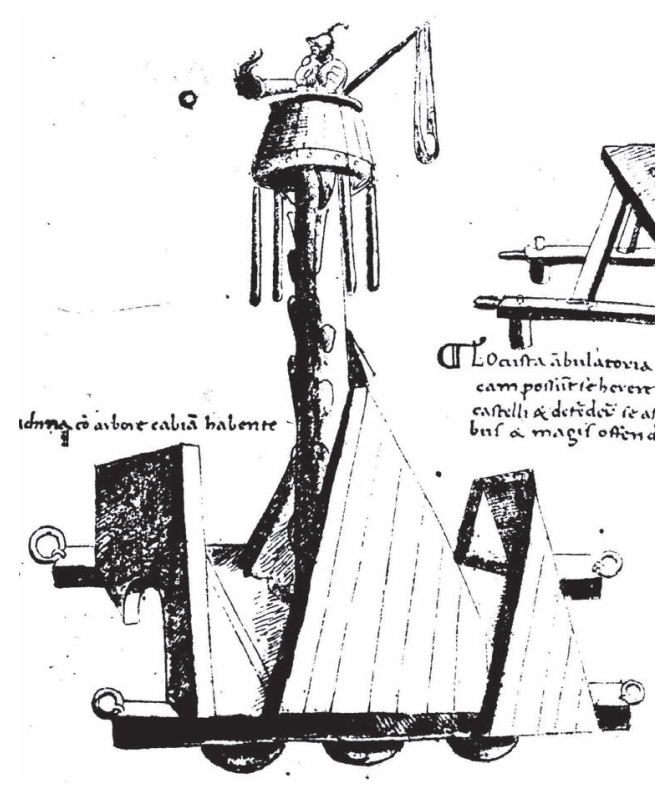

Fig. 39. Máquina de observación. "Il Taccola".

En el diseño de carros de guerra se combinan propuestas imaginativas con otras mucho más realistas: entre estas últimas, se representan algunos tirados por caballos o bueyes y armados con grandes lanzas, hoces o material inflamable; entre las más fantasiosas y técnicamente complejas, sin duda se encuentran los carros blindados dotados de cañones o de artificios lanzallamas (Fig. 40), así como aquellos dotados de sistemas de autopropulsión, bien mediante manivelas (Fig. 41), bien mediante engranajes movidos por las aspas de un molino de viento (Fig. 42), unos modelos cuyos precedentes, como veremos, están en la obra de Guido da Vigevano. 


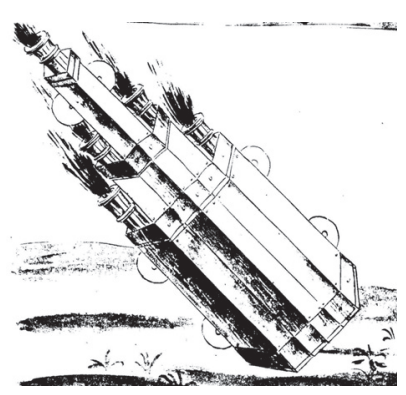

Fig. 40. Carro artillado. "Il Taccola".
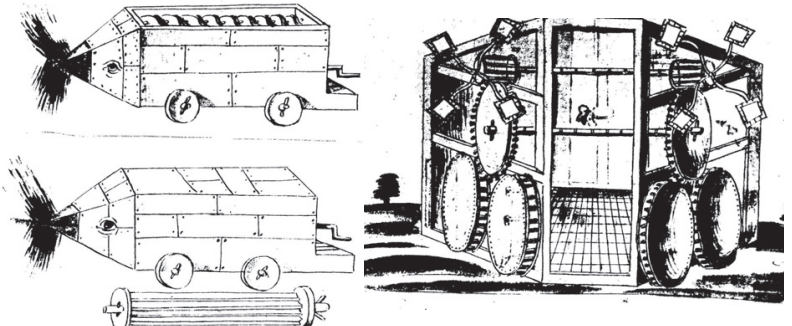

Fig. 41. Carro autopropulsado. "Il Taccola".
Fig. 42. Carro propulsado por el viento. "Il Taccola".

A tenor de los muchos diseños y técnicas ideadas por Mariano Jacopo para acercar el fuego hasta las puertas de las fortificaciones, cabe suponer que aquella operación representaba un problema técnico y militar de cierta envergadura. Por supuesto, había formas simples de hacerlo, como lanzamiento de bolas de fuego mediante hondas, arcos y flechas o su aproximación mediante pértigas portadas por un hombre a pie o a caballo, y todas ellas tienen cabida en sus representaciones. Pero también había soluciones que pasaban por la utilización de máquinas capaces de llevar el fuego y al mismo tiempo proteger a los implicados en la operación. Básicamente, su propuesta consistía en la construcción de un mantelete rodante, en cuyo extremo se colocaba material inflamable, si bien dentro de este modelo genérico cabían muchas variaciones relacionadas sobre todo con el soporte del pebetero y con su sistema de manejo (Figs. 43-45).
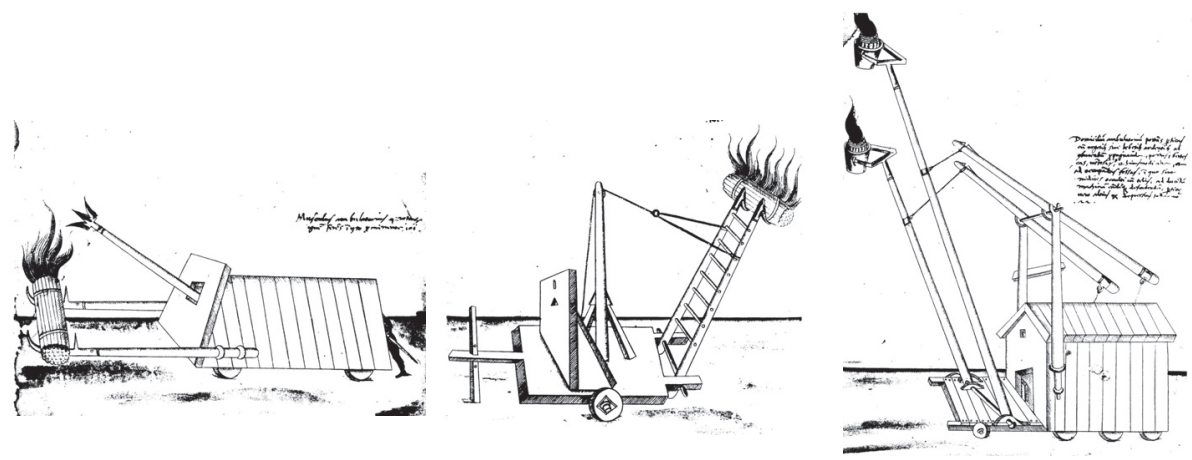

Figs. 43-45. Máquinas de aproximación de fuego. "Il Taccola".

Hay que dejar constancia del buen número de representaciones de armas de pólvora, tanto de las más pesadas como de las portátiles o individuales. Entre las primeras aparecen una gran cantidad de bombardas y morteros de diverso calibre, incluyendo lo que parece una máquina rotativa con varios cañones, si bien, como ya ocurría en el Anónimo de la Guerra Hussita, el autor no parece interesado en abordar los problemas técnicos que pudiera plantear su fabricación, sino en los relacionados 
con su movilidad. De ahí la insistencia en presentar todo tipo de cureñas rodantes, carros o carretilllas para el transporte, así como bancos y otros aparejos para manejarlos y subirlos a los mismos. Entre las armas de fuego portátiles quizás la más reseñable sea la "escopeta" utilizada por un jinete que, para conseguir la estabilidad del arma durante el trote del caballo, ha sido unida a la silla de montar mediante una pieza rígida. Finalmente, hay que hacer notar que el autor recoge diversas fórmulas para elaborar la pólvora para las bombardas, con indicación de sus componentes -salitre, azufre, carbón de sauce, sulfuro de arsénico- y proporciones, el diseño de un molino para triturar la pólvora, y un variado elenco de proyectiles ordinarios, algunos con forma de flecha o torpedo, e incendiarios. En fin, no podemos dejar de señalar que "Il Taccola" puede ser el primer autor en representar el uso de la pólvora en los trabajos de minado de las murallas.

Salvo para el caso de la pólvora para las bombardas, cuya fórmula de fabricación es detallada por el autor y sobre la que ofrece diversos consejos de elaboración, en general los textos que acompañan a los dibujos únicamente suelen ser pequeñas glosas que describen el empleo, utilidad o funcionamiento de las máquinas representadas, pero no sus distintos elementos o su proceso de construcción o montaje. No obstante, las ilustraciones son en muchos casos suficientemente precisas para que un constructor pudiera fabricarlas, lo que otorga al texto un evidente sentido práctico.

Creemos que los cuatro textos glosados dan buena cuenta del desarrollo alcanzado por la producción literaria occidental en materia de ingenios bélicos. Por supuesto no son los únicos y sin duda el panorama está incompleto, pero creemos que al menos resulta revelador de la eclosión experimentada por la literatura técnicomilitar durante el siglo XV. Cabría citar, en todo caso, el Trattato di architettura civile e militari, de Francisco de Giorgio Martini, escrito a finales del siglo XV, ya muy cercano a las inquietudes y los modelos renacentistas ${ }^{30}$, o algunos de los manuales de artillería que comenzaron a circular durante este siglo, como el manuscrito de Johannes Bengedans recientemente publicado procedente de los fondos de la Universidad de Copenhagen -Manuscrito AM 374 fol. de la Colección Arnamagnaean de dicha Universidad- ${ }^{31}$. Pero, especialmente, habría que recordar el De re militari de Roberto Valturio, un ingeniero militar vinculado a la corte de Segismundo Malatesta en Rímini que confeccionó su trabajo hacia 1455 y publicó por primera vez en 1472, si bien en poco tiempo conoció nuevas ediciones, como la que vio la luz en Verona en 1483, lo que demuestra su éxito ${ }^{32}$.

Por la importancia e influencia que tendrá este último texto, el primero de este género en ser impreso, se necesita como mínimo indicar muy brevemente que se trata de nuevo de un "catálogo ilustrado", como lo describe Popplow, en el que no se presentan diseños propios, sino otros tomados de obras anteriores -especialmente de Kyeser, del Anónimo de la Guerra Husita y de los manuscritos de "Il Taccola"-, a cuya tradición literaria pertenece. Ofrece, eso sí, representaciones de mayor calidad y cuidado, que permitían a los profanos en la materia identificar fácilmente las máquinas dibujadas, y renuncia a ofrecer detalles sobre medidas u otras precisiones técnicas. Después de todo, Valturio parece ser más un hombre de letras que un técnico, un humanista en cuya obra se percibe el gusto por lo antiguo más que por lo contemporáneo $^{33}$. Todas las máquinas que encontrábamos en los autores ya citados vuelven a reproducirse, pero con un estilo que denota el interés didáctico del autor -de ahí

\footnotetext{
${ }^{30}$ L. Reti, Francesco di Giorgio, pp. 287-298; P. Galluzzi, Art and Artifice, pp. 49-51.

${ }^{31} \mathrm{~J}$. Bengedans, Kriegskunst.

${ }^{32} \mathrm{R}$. Valturio, De re militari.

${ }^{33}$ M. Popplow, Militärtechnische, pp. 263-265; B. Gille, Les ingénieurs, pp. 91-94.
} 
la escenografía espacial en la que a veces los enmarca- e incluso su pretensión de sorprender a los lectores con diseños no siempre técnicos, pero impactantes, como a título de ejemplo demuestran algunas de las siguientes figuras (Figs. 46-51).

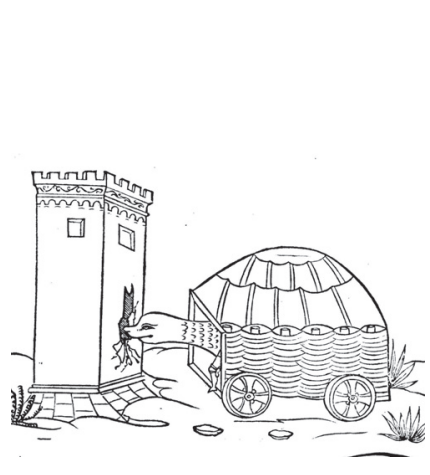

Fig. 46. Ariete. Valturio.

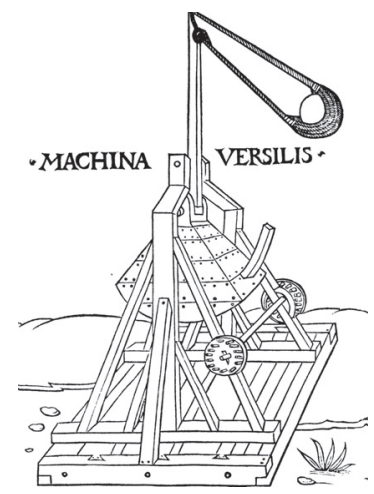

Fig. 47. Trabuquete. Valturio.

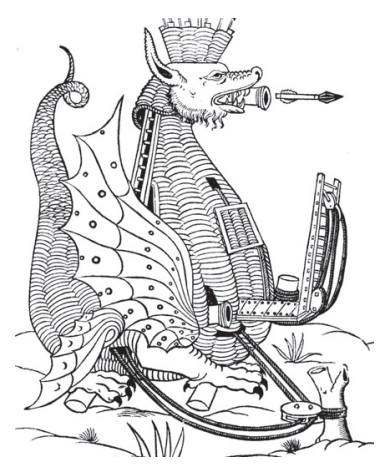

Fig. 48. Torre Artillada. Valturio.

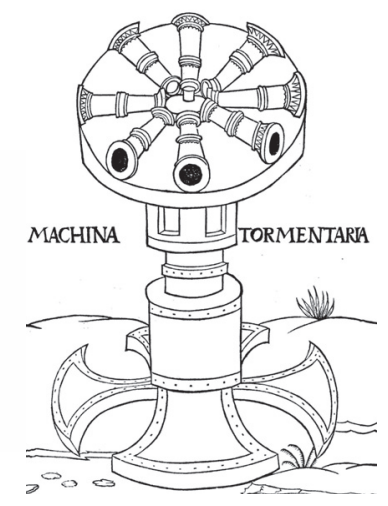

Fig. 51. Cañones sobre plataforma giratoria. Valturio.

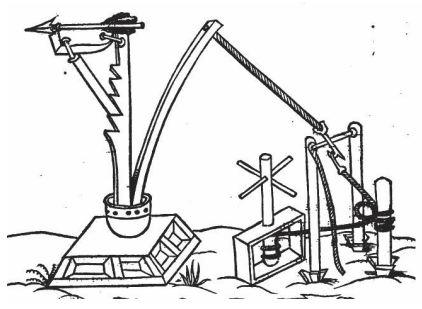

Fig. 50. Catapulta. Valturio.
Fig. 49. Puente de asalto. Valturio.

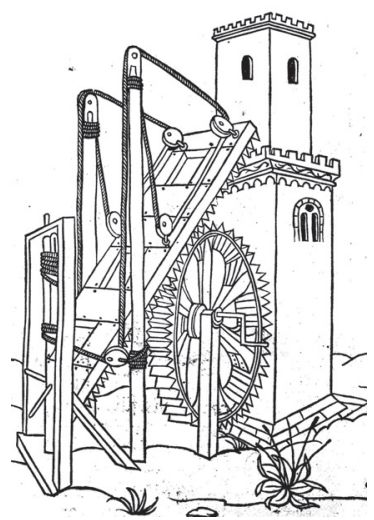

\section{El THeXaurus REGIS FrANCIAE ACQUisitionibus TERRAE SANTAE}

\subsection{El autor y su originalidad}

Los textos y autores del siglo XV que acabamos de comentar contribuyeron de forma definitiva a consolidar un género literario centrado en la tecnología de las máquinas de guerra. Sin embargo, los orígenes de este florecimiento se remontan a la segunda mitad del siglo XIII y encuentra un punto de inflexión en una obra muy original, escrita en 1335 por Guido da Vigevano: nos referimos al texto conocido como 
Thexaurus regis Franciae acquisitionibus Terrae Santae. Se trata de una aportación muy singular por su planteamiento y contenido, que influyó de forma notable en la producción posterior pero que, al mismo tiempo, presenta rasgos particulares que le confieren un lugar privilegiado en la historia de la literatura técnica y del diseño de máquinas bélicas medievales, de ahí la atención que se le prestará en este apartado ${ }^{34}$.

Guido es un autor que encaja perfectamente en el modelo de creador de obras de género técnico que se tiene como característico de la Baja Edad Media: de un lado, es un hombre dedicado profesionalmente a la medicina, con conocimientos de otras materias científicas o técnicas, acostumbrado al manejo de herramientas; de otro, es un personaje que se desenvuelve en un ámbito cortesano, en el que trabaja y donde encuentra el público al que dirige su obra. El mismo perfil, como se recordará, que hallamos en Conrad Kyeser ${ }^{35}$.

Estudió medicina en la Universidad de Bolonia y ejerció como profesional en su ciudad natal, Pavía, y más tarde en diversas cortes europeas, primero en la alemana, al servicio del emperador Enrique VII (1310-1313), después en la francesa -a partir de 1323- como médico de las reinas María de Luxemburgo, mujer de Carlos IV, y Juana de Borgoña, mujer de Felipe VI de Valois. En la corte francesa permaneció al menos hasta 1349. Su vocación médica no fue solo clínica, sino también investigadora -hizo disecciones de cadáveres y experimentó con venenos en busca de antídotos- y académica, destacando como autor de un tratado de anatomía y de una compilación de consejos galénicos ${ }^{36}$.

En 1335 Guido de Vigevano compuso su Thexaurus, un informe dirigido al rey Felipe VI, en el que le proponía el modo para conquistar fácilmente Tierra Santa. Según su propio testimonio, en aquel año se había ordenado una expedición a ultramar con el objetivo de conquistar Tierra Santa, un passagium cuyo jefe sería Felipe VI de Francia. El autor, que consideraba conocer y comprender casi todas las ciencias, quiso realizar su particular contribución a la empresa,

\begin{abstract}
pensando día y noche cómo y de qué modo se podría recuperar Tierra Santa más fácil y rápidamente, dado que los sarracenos están protegidos por muchas aguas, tanto dulces como saladas, y por innumerables villas y castillos fortificados con muros y fosos. Como todo lo bueno y bello procede de lo alto... Dios me ha dado el modo de conquistar fácilmente Tierra Santa de ultramar, el cual escribo para el serenísimo príncipe, el señor Felipe, por la gracia de Dios rey de Francia, porque él es señor de la expedición ${ }^{37}$.
\end{abstract}

La obra adquiere pleno sentido, pues, cuando se inserta dentro los planes bélicos de Occidente para la recuperación de Tierra Santa tras la pérdida de San Juan de Acre en 1291. A pesar de los esfuerzos y del interés del papado y de determinadas autoridades laicas, especialmente de la monarquía francesa, que asumió el liderazgo

\footnotetext{
${ }^{34} \mathrm{El}$ texto se ha conservado en tres manuscritos: el Códice Latino 11015 de la Biblioteca Nacional de Francia, de mediados del siglo XIV; el Códice Mil. Mss. $\left(4^{\circ}\right)$ del Yale Center for British Art, copiado en 1375; y el códice G. V. 9 de la Biblioteca Universitaria de Turín, realizado en el siglo XIX. En este estudio utilizamos y citamos el Códice Latino 11015 de la Biblioteca Nacional de Francia (en adelante Thexaurus). La edición del texto latino de los capítulos sobre máquinas de guerra, acompañada de traducción al italiano y de varios estudios en G. Ostuni, Le Macchine del Re. Una traducción al inglés de estos capítulos en A.R. Hall, Guido da Vigevano.

${ }^{35}$ B.S. Hall, Production et diffusion, pp. 157-170.

${ }^{36}$ Sobre su vida véase G. Ostuni, Le Macchine del Re, pp. 22-28, y la bibliografía allí citada.

37 Thexaurus, f. 32r.
} 
de estos proyectos en las siguientes décadas, ninguna respuesta militar llegó a articularse de manera efectiva. En un contexto de constantes tentativas frustradas, Felipe VI retomó aquellos planes y a partir de 1331 impulsó la iniciativa. Sin embargo, en 1336, fecha prevista la campaña, todos estos planes quedaron en suspenso. Fue precisamente en el ambiente de expectación y de intensos preparativos de estos años en el que Guido da Vigevano elaboró y presentó su informe al rey de Francia ${ }^{38}$.

En realidad, el Thexaurus no sólo se enmarca en un determinado ambiente de exaltación cruzadista, sino también en lo que en 1335 era ya un verdadero género, el de los tratados para la reconquista o recuperación de Tierra Santa. Y es que la incapacidad mostrada por el papado y por las monarquías europeas para organizar de forma efectiva una cruzada en Tierra Santa contrasta con la multitud de planes, consejos y proyectos para llevarla a cabo que se fueron elaborando y presentado en diversas cortes y foros públicos a partir del mismo año de la caída de San Juan de Acre ${ }^{39}$.

Aunque la naturaleza y contenidos de estos programas son muy diversos, la mayoría incide sobre las previsiones organizativas y estratégicas que habrían que tenerse en cuenta para el desarrollo de la cruzada: abundan las recomendaciones sobre los planes de actuación militar, las estimaciones de los efectivos necesarios y su forma de reclutamiento, las necesidades logísticas de la expedición, la determinación del liderazgo político y bélico de la campaña, los cálculos sobre su coste económico o los mecanismos que habrían de ponerse en marcha para reunir los recursos financieros. Los proyectos presentados durante los años finales del siglo XIII y las tres primeras décadas del XIV por una larga lista de personajes de distinta procedencia y formación, así lo demuestran.

Por el contrario, las reflexiones sobre las necesidades o los retos tecnológicos que pudieran plantearse en el desarrollo de los planes están prácticamente ausentes. Sólo en los proyectos más detallados y documentados podremos encontrar alguna indicación al respecto, pero siempre de forma muy genérica o tangencial. Es el caso de las propuestas de Ramón Llull: considerado por algún especialista como the most original and certainly the most wide ranging of crusade theorists, sus ideas sobre la recuperación de Tierra Santa abarcan un amplio espectro de consejos de todo tipo -militares y no militares-, pero apenas si ofrece alguna indicación sobre las máquinas de guerra, más allá de indicar la superioridad de los cristianos sobre los musulmanes en este terreno o la necesidad de nombrar a un encargado de la madera bajo cuya responsabilidad estarían los barcos, las máquinas, los escudos y las ballestas ${ }^{40}$.

Quizás la única excepción sea el Liber secretorum fidelium crucis presentado por Marino Sanuto Torsello el Viejo al papa Juan XXII en 1321. No en balde el texto de Sanuto ha sido considerado dentro de este género literario como el más concienzudo y práctico de todos los informes, de modo que difícilmente podía olvidar las necesidades técnicas implícitas en la guerra ${ }^{41}$. El autor no solo señala la necesidad de llevar personal especializado para la fabricación de ingenios y ballestas, así como cortadores de piedras para la elaboración de proyectiles y la excavación de minas, sino que también dedica todo un capítulo a describir el modo de construir castillos de madera y grandes ballestas de sitio, con indicación de sus medidas y materiales, así como de algunos datos del proceso de montaje. Pero hay que reconocer que, en el

${ }^{38}$ N. Housley, The later crusades, pp. 22-39; para los planes de cruzada de Felipe VI véase J. Tyerman, Philip VI.

${ }_{39}$ S. Schein, Fidelis Crucis.

${ }^{40}$ N. Housley, The later crusades, p. 29; W. Altoé, E. Ventorim, R. da Costa, Raimundo Lúlio, pp. 76-77, 84-84 y 106-107.

${ }^{41}$ M. Sanuto, Liber vol. II. El juicio sobre el trabajo es de N. Housley, The later crusades, p. 36. 
conjunto de la obra, estas referencias están muy diluidas y, desde luego, en absoluto constituyen el elemento nuclear de sus reflexiones ${ }^{42}$.

Así pues, aún insertándose en este género literario y compartiendo los objetivos generales de todas las anteriores propuestas -el título del tratado y su introducción no dejan lugar a duda sobre esta cuestión-, hay que reconocer que la propuesta de Guido es completamente original y no encuentra paralelo. Y ello es así porque se desentiende de todos los temas que interesaban al resto de los personajes que escribieron tratados sobre la recuperación de Tierra Santa y se centra, por el contrario, en otros que normalmente no aparecen en aquellos.

A tenor de la estructura y del contenido del Thexaurus, parece claro que la pretensión del médico fue ofrecer soluciones a dos conjuntos de retos que él suponía que se le plantearían a los cruzados en el curso de la expedición, uno de carácter médico y otro de tipo técnico-militar. Consecuentemente la obra aparece dividida en dos partes: en la primera el autor, partiendo de la idea de que nada puede hacerse sin la salud del cuerpo y de que ésta sólo puede preservarse gracias al arte médico, compone un pequeño compendio de medicina con el que pretende que el rey de Francia pueda completar su viaje con buena salud y protegerle de los venenos. La información contenida en esta primera sección procede fundamentalmente de Galeno, pero también hay alguna aportación original relacionada con el tratamiento de los calambres en los pies y las piernas que solía afectar a los caminantes - un problema que debía de ser habitual entre los cruzados-, con la fabricación de antídotos contra los venenos, especialmente contra el acólito - un asunto que debía preocupar en las cortes europeas- o con el buen estado de la comida ${ }^{43}$.

La segunda parte del texto es la que constituye el núcleo de su obra, por cuanto contiene el modus leviter conquirendi terram sanctam o la scientiam predictam aquisitionis terrae sancte, un método que el autor considera una novedad que hasta entonces nadie había descubierto ${ }^{44}$. En resumen, lo que detalla en estos 13 folios $(41 \mathrm{r}-54 \mathrm{v})$ no son sino una serie de respuestas tecnológicas a algunos de los desafíos a los que, según creía su autor, tendrían que hacer frente los expedicionarios.

Estos retos, tal como eran concebidos por Guido da Vigevano, procedían básicamente de dos circunstancias: primero, del hecho de que la conquista de puntos fuertes requeriría el concurso de diversos dispositivos - artificiis - que ayudaran a su rápida anexión; segundo, de la necesidad de cruzar sin retraso cursos de agua, para lo cual también habrían de emplear algunos artefactos. El problema radicaba en la grave dificultad que suponía transportar por mar unos instrumentos tan pesados, razón por la cual propondrá un sistema de construcción que permitiera tanto aligerar la carga de material como su fácil transporte a caballo y su rápido montaje A tal fin redactará 13 capítulos, en cada uno de los cuales describirá la forma de construcción de un artefacto y dibujará ilustraciones para aclarar el texto ${ }^{45}$.

Está claro, pues, que el contenido del Thexaurus, por su especialización, se aparta de los que habitualmente se encuentran en otros proyectos "de recuperación", pero al mismo tiempo hay que señalar que también presenta una innegable singularidad respecto a los tratados técnicos que habrían de desarrollarse a lo largo del siglo $\mathrm{XV}$ y de los que este texto es predecesor en muchos sentidos.

${ }^{42}$ M. Sanuto, Liber, vol. II, pp. 78-81.

${ }^{43}$ Thexaurus, ff. 32r-41r. Un resumen de los capítulos "médicos" en B. S. Hall, Guido da Vigevano, pp. 36-41.

${ }^{44}$ Thexaurus, f. 32 r.

${ }^{45}$ Ibidem, f. 41r. Sobre la técnica de representación de los dibujos véase S.Y. Edgerton, The Renaissance, p. 174; P. Galluzzi, Art and Artifice, p. 257. 
Tal originalidad puede apreciarse en varios aspectos de la obra, tales como el tipo de público al que está dirigida, la intención del autor y la naturaleza del texto. Como ya hemos tenido ocasión de comentar, en su momento Bert S. Hall hizo referencia al cambio que parece producirse hacia el siglo XIV en la autoría y la audiencia de los textos técnicos: frente a los pocos artesanos que, anterioridad a estas fechas, habían puesto por escrito sus conocimientos dirigiéndolos a otros expertos, a partir de entonces surgen una serie de autores -no necesariamente artesanos- que aspiran a difundirlos entre un público más extenso y no especializado. Guido entraría de lleno en esta categoría: después de todo, el texto fue dirigido al rey de Francia, y es posible que, como otros proyectos "de recuperación", fuera presentado y discutido en la corte. En la misma línea, Popplow considera a esta obra dentro los catálogos de dibujos que no estaban destinados a la instrucción de otros especialistas, sino a un público profano en la materia, deseoso de conocer y de entretenerse con las propuestas de unos autores más interesados en su promoción cortesana que en ofrecer instrucciones técnicas a los potenciales ingenieros-constructores ${ }^{46}$. En consecuencia, desde este punto de vista la obra no presentaría mayor originalidad respecto a los tratados del siglo $\mathrm{XV}$, de los que en todo caso sería una precursora.

Sin embargo, creemos que el Thexaurus presenta algún matiz que conviene subrayar. Siendo innegable que estaba dirigido a un público cortesano y que, por tanto, necesariamente tenía que presentar una vertiente didáctica, también es cierto que Guido da Vigevano diseña sus aportaciones pensando no en una mera presentación enciclopédica, sino en una futura construcción. Bastaría con acercarse a las descripciones de piezas y a las instrucciones de montaje de cualquiera de los dispositivos para comprender que difícilmente podrían estar destinadas a la corte del rey de Francia, que seguramente no las entenderían.

Estos textos parecen dirigidos más bien a un personal experto, a los maestros que dominaban el arte de la carpintería o de la construcción, incluyendo a los fabricantes de molinos, a cuya habilidad y conocimientos recurre más de una vez para culminar el montaje. Precisamente D. McGee ha llamado la atención sobre el hecho de que en alguna ocasión Guido da Vigevano se muestra consciente de que sus aclaraciones eran insuficientes, pero comprensibles para los técnicos en los que parece estar pensando: por ejemplo, en el capítulo VIII, al describir el modo de hacer unos barcos reconoce, tras ofrecer una explicación un tanto oscura, que el prudente [constructor] fácilmente podrá entender todo esto, porque no puedo escribirlo de manera más clara (f. 48v). No pocas veces hace referencia explícita a la intervención de los maestros artesanos en el proceso de construcción de las máquinas, a cuya experiencia se apela y a quienes consideraba no solo capaces de entender los detalles más técnicos o menos explícitos, sino también de mejorar el diseño -así en los capítulos II, V, XI y XII, por ejemplo-. De ahí se derivaría que el autor elaboraba su obra no sólo para su patrón -el rey- y para una audiencia cortesana, sino también para los expertos, lo que le obligaba a combinar imágenes didácticas y textos muy técnicos, un rasgo que le diferenciaría de muchos de los tratados tecnológicos posteriores y que contribuye a su originalidad ${ }^{47}$.

Hay un aspecto de su contenido que viene a subrayar su singularidad respecto a otras obras de tecnología: la novedad de sus propuestas. No se trata tanto del hecho de que Guido fuera imaginativo e inventara determinadas máquinas o instrumentos de uso militar, o de que propusiera modelos más o menos originales, aunque

${ }^{46}$ B.S. Hall, Giovanni de'Dondi, pp. 140-141; M. Popplow, Militärtechnische, pp. 253-254 y 257-258.

${ }^{47}$ D. McGee, The Origins, pp. 63-66. 
fueran de imposible ejecución o uso ineficiente, algo que también encontraremos en los textos posteriores, sino de que en el proceso de fabricación introduce innovaciones técnicas que carecían de precedentes. A este respecto, varias son las novedades que los historiadores de la tecnología han podido constatar en sus diseños, entre las que han destacado las siguientes ${ }^{48}$ :

1.- El uso de piezas prefabricadas, modulares, portátiles, plegables o desmontables, e intercambiables de un dispositivo a otro. En esto radica la facilidad del traslado de materiales -a lomos de caballos-, el ahorro en la cantidad de material transportable y la rapidez del montaje, que eran los objetivos perseguidos por Guido.

2.- La utilización de armazones cubiertos de cuero o de barriles para reforzar la flotación de los cascos de los barcos.

3.- El empleo de cigüeñales para mover las ruedas hidráulicas o aspas para propulsar barcos.

4.- La frecuente utilización del hierro en las estructuras y en muchos de los componentes -bisagras, clavos, ganchos, barras, piñones y ruedas dentadas-.

5.- La descripción por primera vez de un ascensor o mecanismo de autoelevación de una plataforma, basado en un sistema de poleas y cuerdas accionadas por tracción humana.

6.- La aplicación pionera de un sistema de cigüeñales, engranajes y ruedas dentadas para conseguir la autopropulsión de un carro de guerra.

7.- La insólita adopción del mecanismo de funcionamiento del molino de viento para la propulsión de un carro de guerra.

Salvo alguna excepción -caso del empleo de cigüeñales para transmitir movimiento-, las bases técnicas sobre las que se soportaban estas propuestas no eran novedosas en sí mismas, sino que más bien formaban parte del cuadro tecnológico de su época. Lo innovador era su empleo en la construcción y diseño de máquinas de guerra. No hay constancia de que en la práctica estas propuestas llegaran a aplicarse en tiempos del autor y muchos de sus diseños -las piezas prefabricadas, los barcos de aspas o los carros de combate autopropulsados- tardarían siglos en irrumpir en el panorama técnico de la guerra, de ahí que hayan sido consideradas como fantasías imaginativas, pero ello no le resta valor al grado de inventiva e innovación que demuestra $^{49}$.

\subsection{Artefactos y máquinas}

Hemos optado por presentar a los dispositivos en virtud de su funcionalidad, por lo que los agruparemos en cuatro categorías de artefactos: artilugios de protección, máquinas de escalo y asalto, carros de combate y sistemas para navegar o atravesar corrientes de agua.

Por lo que respecta a la primera, Guido da Vigevano presenta dos tipos de artilugios diseñados para ofrecer protección a los guerreros en diversos contextos. El primero es un dispositivo o estructura defensiva -edificia custodie- ideada para dar refugio y seguridad a los atacantes contra las flechas de los enemigos cuando se acercaban a las murallas. Responde al modelo de mantas, viñas o gatas, encontrándose la novedad no en el instrumento en sí, sino en algunos rasgos de su construcción: son ligeros, desmontables o plegables y transportables a caballo.

\footnotetext{
${ }^{48}$ A.R. Hall, Guido's Texaurus, pp. 14-15.

${ }^{49}$ B.S. Hall, Giovanni de'Dondi, pp. 136-139.
} 
Se proponen dos variantes: la primera se fabrica con una doble tela de algodón cuya resistencia a las flechas se refuerza mediante una impregnación de limaduras de hierro. Tanto el tratamiento que han de recibir las limaduras hasta convertirse en polvo como el proceso de impregnación en las telas mediante masilla, son detalladamente explicados. Una vez elaborada era colgada de una pértiga horizontal ad modum cortine mediante anillas, y esta a su vez era suspendida por otras dos pértigas verticales sujetadas manualmente. A lo largo de la tela debían abrirse saeteras para que los guerreros pudieran ver y disparar a los enemigos amparados tras la cortina (Fig. 52, izq.).

Contra el impacto de los proyectiles de grandes ballestas se propone otra variante más sólida, a la que denomina "puerta": un parapeto formado por el ensamblaje de varias tablas que eran unidas mediante bisagras. El "artificio" estaba dotado de saeteras y podía reforzarse en el interior con una plancha de hierro (Fig. 52, der.). Esta forma de composición de un entablamento es la que volveremos a ver en la construcción de otros ingenios, de modo que las mismas tablas e idéntico sistema servían para la formación de aquellos, dando así cuenta del carácter multiuso e intercambiable de los elementos utilizados ${ }^{50}$.

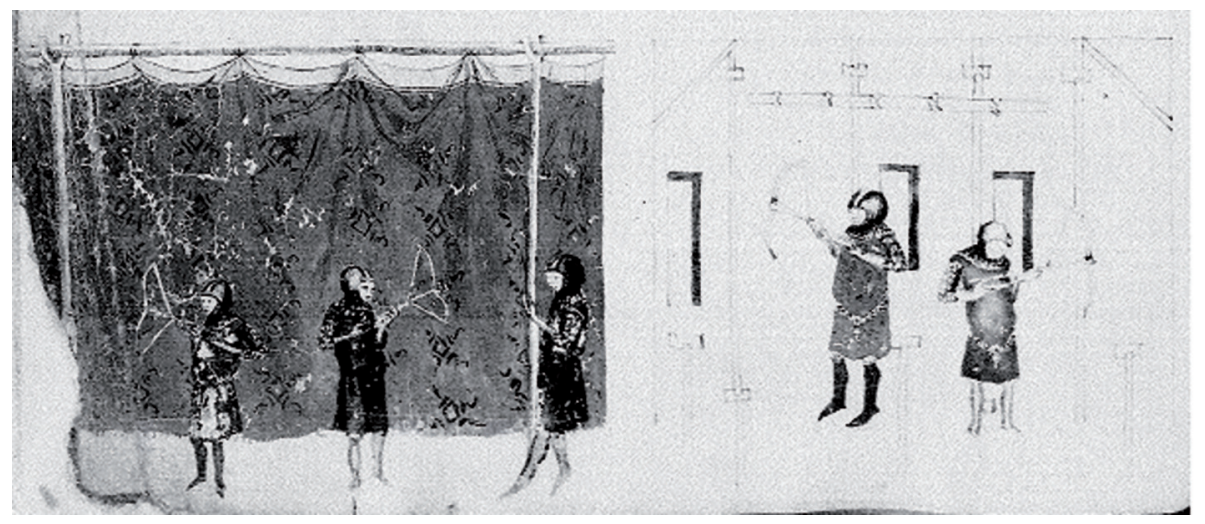

Fig. 52. Mantas. Thexaurus, f. 41v.

El segundo tipo de artilugio protector es la panthera, diseñado para que pocos hombres pudieran retener o mantener a distancia a grandes contingentes enemigos en campo abierto. También se presentan dos variantes: la primera es una estructura de forma triangular, formada mediante el ensamblaje de tablas de madera unidas mediante bisagras de hierro. Cada tabla tiene una saetera, así como una serie de anillas y barras en el interior que permiten moverla a pulso. Para dar firmeza a la estructura, dos pértigas recorren longitudinalmente los entablados de los lados largos del triángulo isósceles. La parte superior puede cubrirse con una tela reforzada como la ya descrita. La base del triángulo permanece abierta para que se pueda dar a la pantera el ancho que se considere oportuno, si bien está protegida por dos pértigas unidas a

${ }^{50}$ Thexaurus, cap. I, f. $41 \mathrm{v}$. 
dos anillas. En la parte exterior, para mantener alejados a los enemigos, se colocan unas estructuras prefabricadas de puntas de hierro clavadas a unos postes que se atan al artilugio (Fig. 53) $)^{51}$.

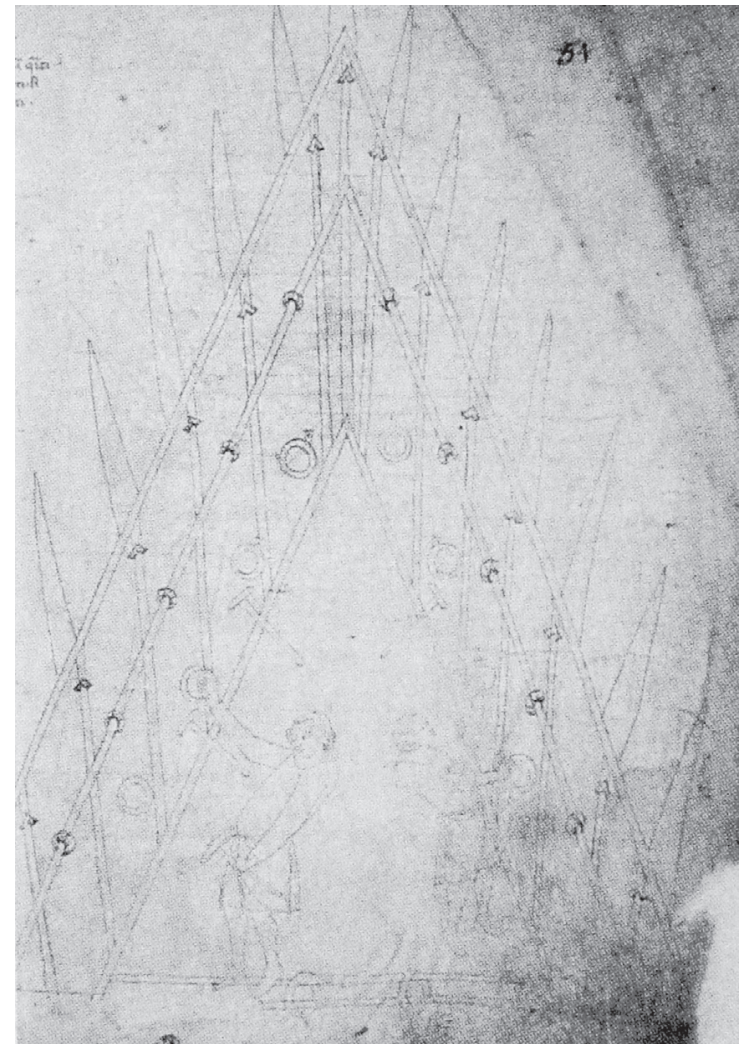

Fig. 53. Panthera. Thexaurus f. 54r.

La segunda variante de la pantera es de mayor tamaño y con forma pentagonal. El sistema de construcción es el mismo, pero el artificio es lo suficientemente ancho como para acoger en su interior a un carro de bueyes sobre el que puede colocarse un pequeño ingenio para lanzar piedras en todas direcciones -una mangavela (Fig. 54) $)^{52}$.

${ }^{51}$ Thexaurus, cap. XIII, f. 53r.

${ }^{52}$ Thexaurus, cap. XIII, f. 53r-v. 


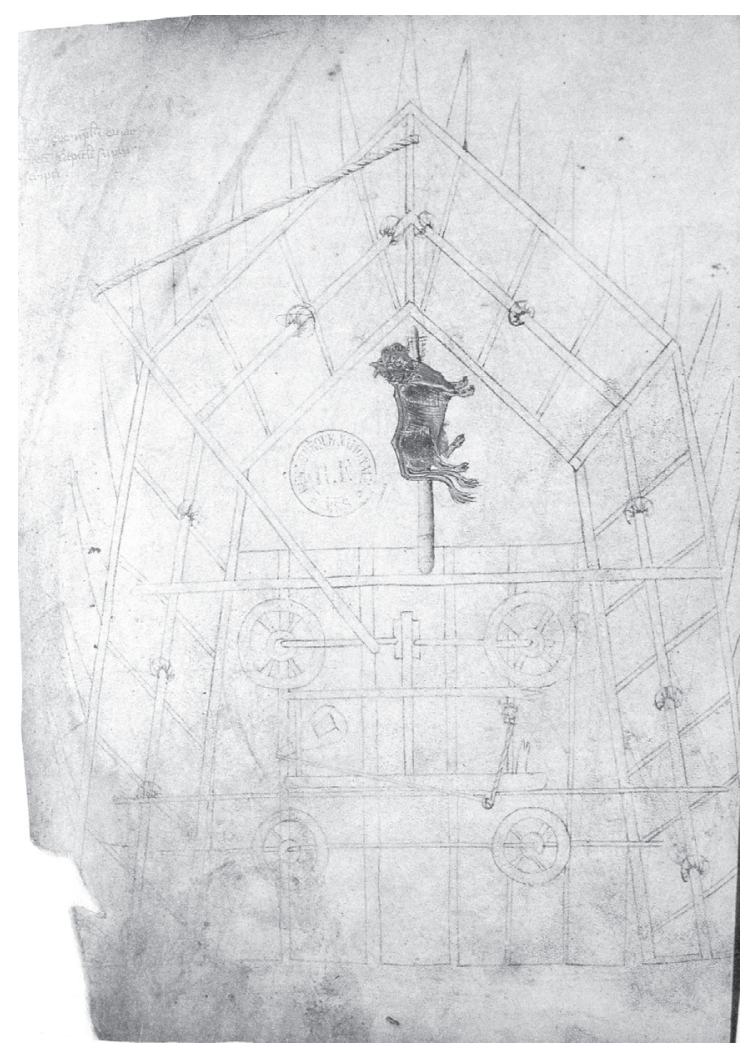

Fig. 54. Panthera. Thexaurus, f. 54v.

Este tipo de cercas podía servir para proteger a un pequeño grupo de hombres en medio de una multitud de enemigos, pero Guido además estaba convencido de que con unos cuantos de estos dispositivos unos pocos guerreros podían confundir a un gran ejército. Más aún, consideraba que con ellos se podía formar una barrera que impidiese el paso a los adversarios: para ello bastaría con colocar entre un carro y otro una pértiga reforzada con puntas de hierro, de modo que abarcara un amplio espacio - una legua o más ${ }^{-53}$.

Dentro de la categoría de máquinas de escalo y asalto el autor expone una gama más variada de artificios, y en todos ellos volvemos a encontrar las características técnicas que singularizan a las propuestas de Guido da Vigevano: siempre son dispositivos ligeros, desmontables o plegables, formados por módulos intercambiables de un aparato a otro -multiuso- y fácilmente transportables a caballo.

A uno de los que le dedica mayor atención es al gran poste de madera al que denomina pertica. El interés que le otorga deriva del hecho de que su sistema de construcción es el mismo que utilizará en otros artefactos, con lo que se convierte

\footnotetext{
${ }^{53}$ Thexaurus, cap. XIII, f. 53v.
} 
en una pieza clave de su propuesta tecnológica, hasta el punto de reconocer que hec pertica isto modo operata est fundamentum totius acquisitionis ipsarum terrarum ${ }^{54}$.

La pertica es un artefacto compuesto por un gran poste rematado por un pequeño castillo de madera, desde donde los asediantes de una ciudad fortificada o una fortaleza pueden atacar a los defensores situados sobre las murallas o incluso intentar el asalto (Fig. 55).

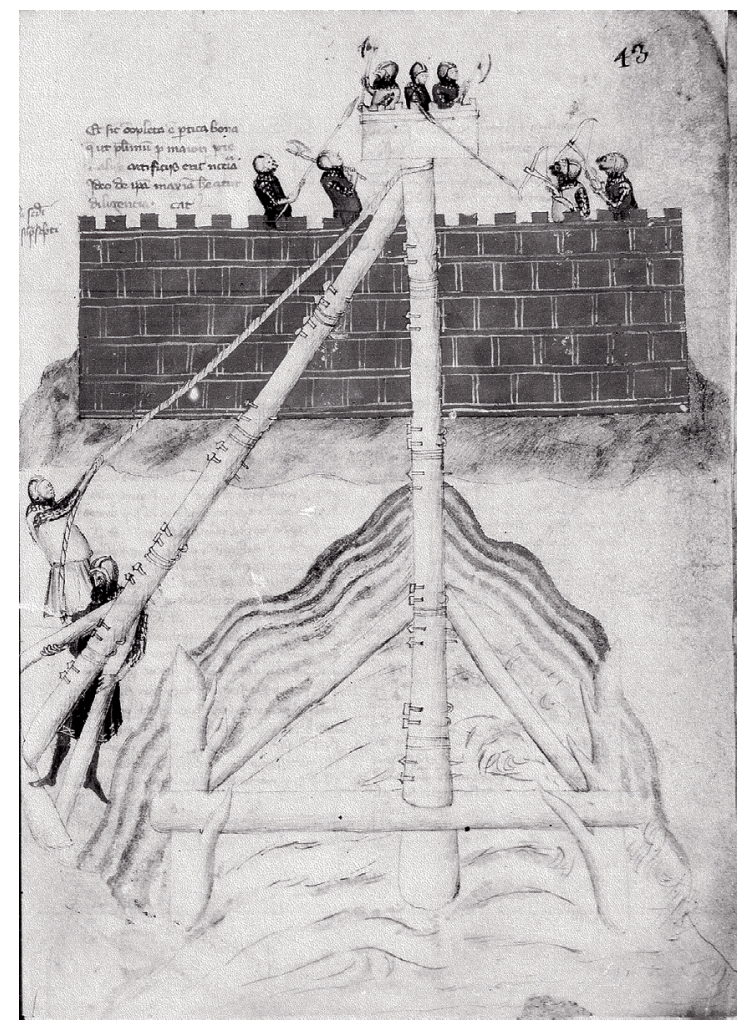

Fig. 55. Pértiga. Thexaurus, f. 43r.

El interés radica en su modo de construcción: la columna se erige a partir de la unión de un determinado número de secciones o troncos -trunci-de buena madera, de más de medio metro de alto - uno brachio et dono semisse ${ }^{55}$ - y tan ancho como la pierna de un hombre. La clave de toda la composición estaba en la forma de ensamblaje: un mecanismo machihembrado en el que un perno de hierro entraba en las dos

54 Thexaurus, cap. II, f. 42r.

55 A.R. Hall traduce "brachium" como media yarda $(0.4572 \mathrm{~m}$.) y "semissis" como medio pie (0.1524 m.). De ser correcta su propuesta, cada tronco mediría $0.762 \mathrm{~m}$. de alto, véase A.R. Hall, Guido's Texaurus, p. 16. 
secciones que habían de unirse y era fijado por clavos que atravesaban tanto la madera como el perno. Para darle una mayor estabilidad a la unión, la junta se aseguraba con una banda de hierro que la abrazaba y todo el conjunto se reforzaba con otras tiras de hierro y con cuerdas.

Una vez montado, se hacía en uno de sus extremos un pequeño castillo o torreta circular - balitrisca rotunda-, capaz de albergar a uno o dos hombres. Ésta se fabricaba con una plataforma redonda de madera y una pared de tablas unidas con bisagras, de forma que pudiera plegarse para su traslado. Cuatro puntales servían para fijar la torreta al poste, mientras que dos poleas situadas en el extremo de la pértiga, accionadas por dos cuerdas, se utilizaban para izar el conjunto.

También era necesario crear una base formada por dos gruesos troncos cruzados en cuyo centro se hacía un agujero donde encajaba el pie de la pértiga. Una vez compuesta la pértiga, se acercaba hasta el lugar de la muralla que se quería asaltar: era entonces cuando se fijaba la torreta al poste, este se levantaba gracias a las poleas y las cuerdas, y finalmente se fijaba a la base. La operación resultaba más complicada cuando entre los asaltantes y los asediados se interponía un foso, pues entonces el poste tenía que inclinarse para alcanzar la muralla. En tal caso, Guido proponía remedios adicionales: primero, para que la plataforma se mantuviese horizontal respecto al suelo cuando la pértiga se inclinase, era necesario fijarla al poste oblicuamente; segundo, para que el poste pudiera inclinarse, se requería una base más compleja, formada por un tronco grueso donde se colocaba el pie de la pértiga y por dos puntales inclinados; por último, si por la longitud del poste resultaba difícil mantenerlo de pie, se construía una segunda pértiga de soporte, con su pie y sus puntales, que se unía al primero mediante un perno de hierro ${ }^{56}$.

La misma propuesta tecnológica, que aspira a crear artefactos complejos a partir de módulos desmontables y fácilmente transportables a caballo, encontramos en el diseño del puente de asalto: una rampa inclinada que, colocada sobre el parapeto de un muro, permite a los atacantes asaltarlo (Fig. 56). Como en el caso de la pértiga, el interés radica en su técnica de construcción: una serie de tablas unidas mediante bisagras o goznes de hierro. Este armazón se refuerza con cuatro gruesas cuerdas que ensartan a los tablones a través de unos agujeros y que recorren todo el entablado longitudinalmente. Para darle mayor rigidez, por la parte inferior se colocan unas palancas de madera tan gruesas como lanzas. El dispositivo se completa colocando parapetos a ambos lados que den seguridad a los asaltantes ${ }^{57}$.

${ }^{56}$ Thexaurus, cap. II, ff. 42r-43r.

${ }^{57}$ Thexaurus, cap. III, f. $43 \mathrm{v}$. 


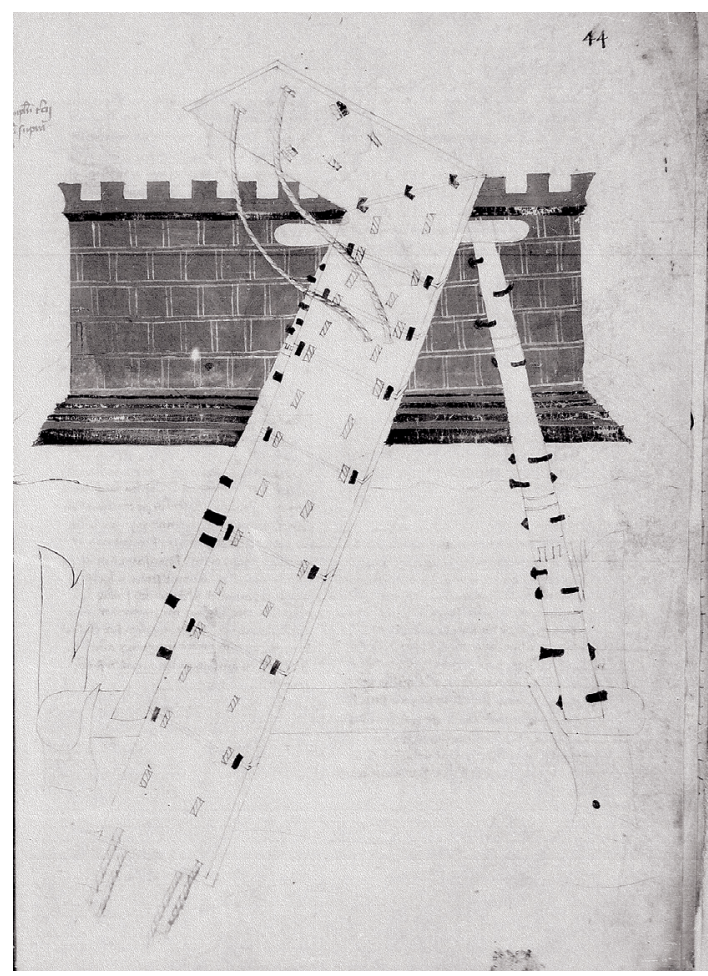

Fig. 56. Puente de asalto. Thexaurus, f. 44r.

Para atravesar el foso de una fortaleza, el puente se apoya sobre un andamio formado por una viga horizontal que se sostiene sobre dos largos postes compuestos con el mismo mecanismo de ensamblaje que las pértigas. Por último, para facilitar el asalto se construye en el extremo de la rampa un puente levadizo, hecho con idéntico sistema al empleado en el anterior y unido a él mediante bisagras. Este sistema permitía plegar el puente y transportarlo a lomo de caballo. Además, cada elemento -tanto las tablas como los troncos que forman el andamio-, era reutilizable en otros dispositivos.

Las escalas que aparecen en la panoplia de Guido responden a dos modelos, el primero de ellos formado por dos escaleras unidas rematadas por un puente de asalto (Fig. 57). Para la composición de cada escalera se emplean dos postes modulares como los ya descritos, a los que se unen en sus caras interiores dos cuerdas de la misma longitud. Los peldaños se construyen en madera con los extremos de hierro y se ensartan en las cuerdas longitudinales. Las dos escaleras se unen en el extremo superior mediante un eje. El dispositivo se completa con un puente levadizo fabricado con los mismos materiales y método de composición del ya descrito, puente que es subido y bajado gracias a un sistema de poleas y cuerdas accionado desde tierra por dos operarios. Una vez más el autor insiste en la ventaja de que todo el ingenio puede ser desmontado, las escaleras embaladas y llevadas en bestias ${ }^{58}$.

\footnotetext{
${ }^{58}$ Thexaurus, cap. IV, f. 44v.
} 


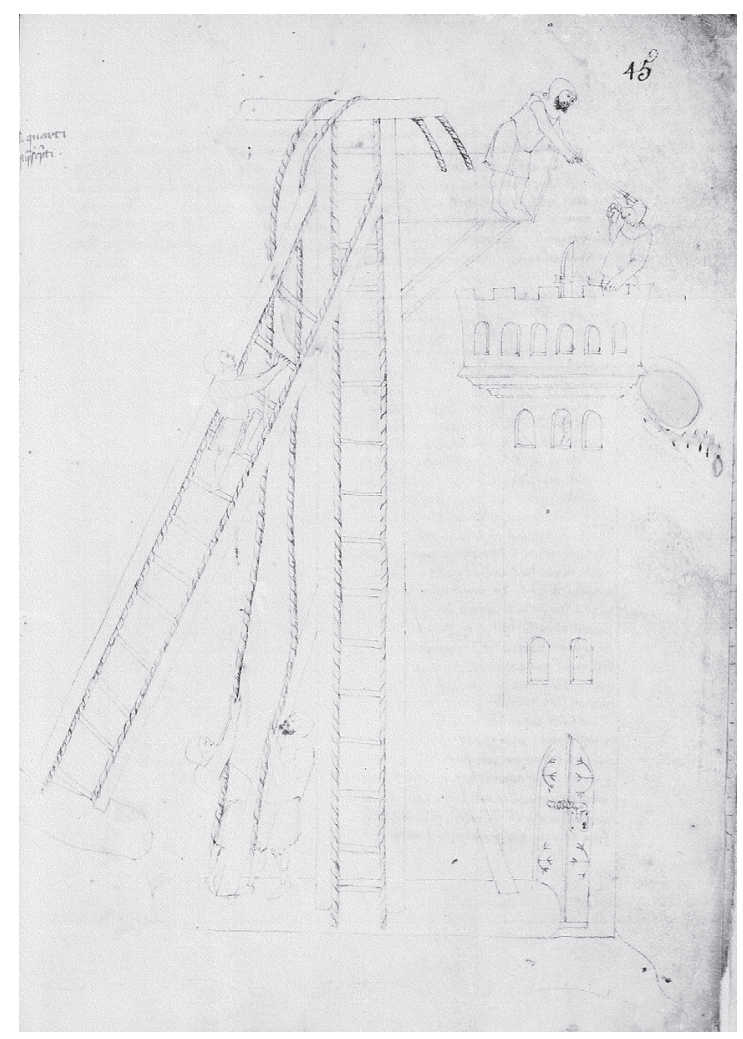

Fig. 57. Escala con puente. Thexaurus, f. 45r.

Guido propone un segundo tipo de escalas especialmente diseñado para que pudiera montarse en secreto y rápidamente, además de ser transportado con facilidad. Por su morfología esta variante se diferencia de la anterior en que, en vez de ser rematada por un puente levadizo, lo es por una torreta de madera (Fig. 58) ${ }^{59}$. Su construcción no varía respecto a lo ya conocido - la escala descrita anteriormente y la torreta de madera que acompañaba a la pértiga-, lo que viene a demostrar la virtualidad de la técnica modular y multiuso de Guido da Vigevano. Quizás lo único resaltable sea que el autor detalla el modo de fijación de los peldaños en las cuerdas: en los extremos de aquellos se realizan agujeros que sirven para enlazar con unas anillas insertas en las cuerdas longitudinales. Los postes son desmontables, las cuerdas y peldaños enrollables y las paredes de las torres plegables, de modo que, según calcula el autor, un solo caballo puede transportar 15 o 20 escalas con torretas, o entre 30 y 40 si no están dotadas de torretas.

\footnotetext{
${ }^{59}$ Thexaurus, cap. V, f. 45v.
} 


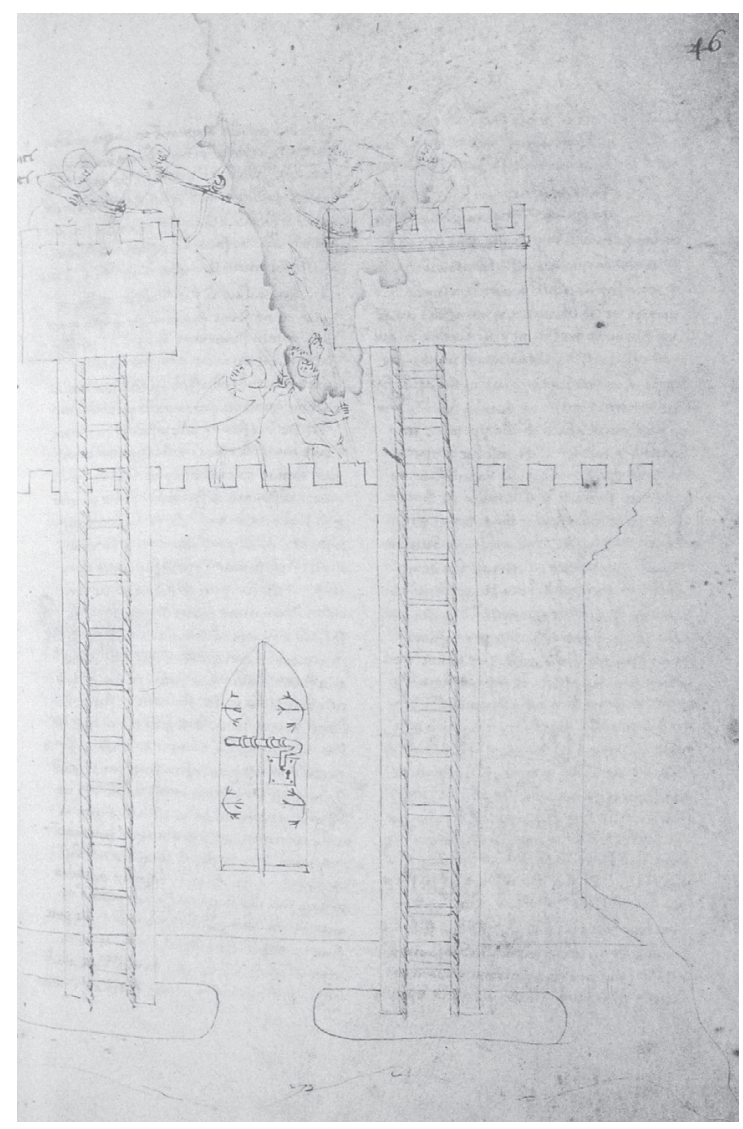

Fig. 58. Escala con torreta. Thexaurus, f. 46r.

En la categoría de máquinas de asalto encontramos una singular propuesta: una torre de madera autoelevable que alcanza una altura superior a la muralla que pretende asaltar gracias a un sistema de poleas y cuerdas que permite su elevación manejándolo desde el interior (Fig. 59) ${ }^{60}$. La idea no era nueva, puesto que ya Vegecio hablaba de un artificio en el que en el interior de una torre se construye otra más pequeña que se alza mediante un sistema de cables y poleas ${ }^{61}$, pero la propuesta de Guido resuelve el problema técnico de manera original: aquí el sistema se soporta sobre un gran tablero que sirve de base para la construcción de un castrum o domus incastellata de madera. Éste se apoya sobre dos grandes postes que lo atraviesan a través de unos orificios practicados en el suelo y el techo del mismo, y dos poleas situadas en la parte superior de los postes permite a los operarios situados en el interior elevarlo mediante cuerdas. En un segundo modelo, a las poleas interiores se añaden otras dos exteriores

${ }^{60}$ Thexaurus, cap. VI, ff. 46v-47r.

${ }^{61} \mathrm{M}^{\mathrm{a}} \mathrm{F}$. Barrio, Edición crítica, Lib. IV, cap. XIX. 
que son accionadas desde fuera de la domus al tiempo que se hace desde dentro (Fig. 60). Básicamente, pues, el mecanismo funciona como un ascensor manual.

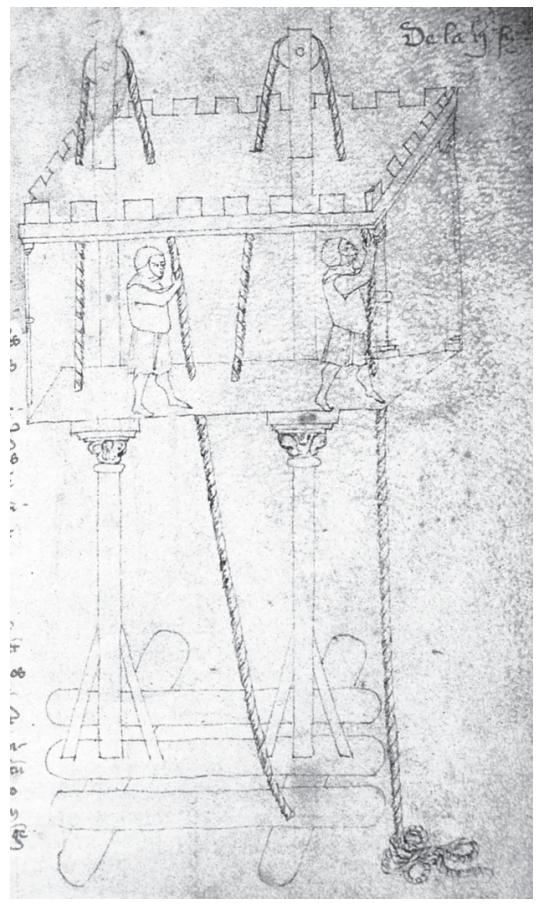

Fig. 59. Torre elevable. Thexaurus, f. 47r.

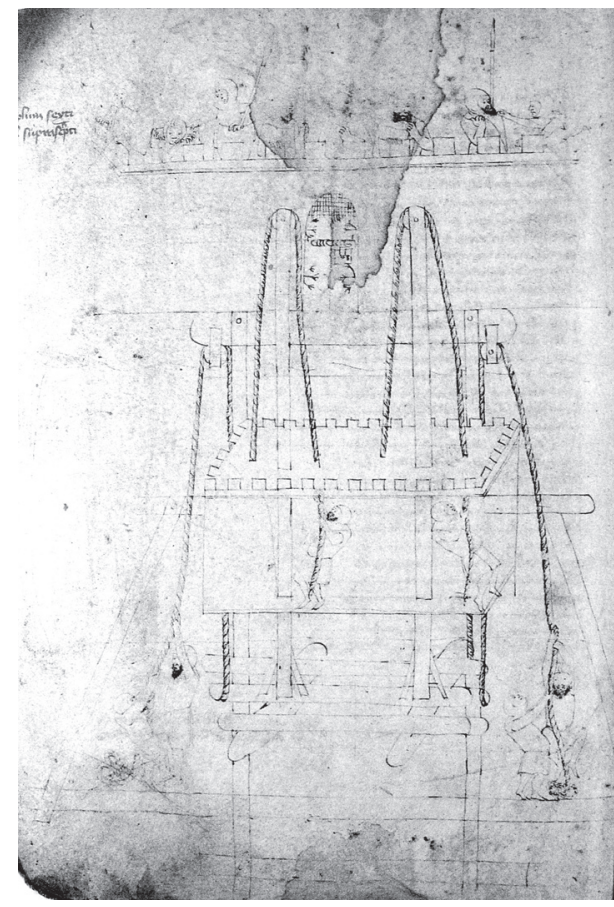

Fig. 60. Torre elevable. Thexaurus, f. $47 \mathrm{v}$.

El artefacto se completa con cuatro ruedas, en tanto que su movimiento se consigue mediante tracción humana, sirviéndose de un juego delantero de poleas y de cuerdas que toma como punto de apoyo un poste. Para salvar un foso se construirá sobre él un andamiaje a base de pértigas -cruzando varios postes- y para que el castrum se desplace se colocarán encima de estas vigas unas planchas de madera sobre las que circulará la torre. Nada de ello se aprecia en los dibujos. Aparte de lo ingenioso del sistema de elevación, una vez más el autor insiste en las ventajas de construir una máquina completamente desmontable, fabricada por módulos -los postes según el sistema de "troncos" y la casa fortificada mediante tablas ensambladas con bisagras y pernos-, que podía ser manejada por quince hombres y transportada por piezas a caballo.

Las propuestas que han dado mayor proyección a Guido en el ámbito de la historia de la tecnología son las que cabe incluir en la categoría de carros de combate, porque por primera vez se diseña un tipo de vehículo para cuyo movimiento no se requería tracción animal. Dos son los modelos diseñados y los dos están pensados para desordenar y confundir a las tropas enemigas en el campo de batalla: cum furore magno curret per campos confundendo magnum exercitum cum modica gente, se dice de uno de ellos ${ }^{62}$.

${ }^{62}$ Thexaurus, f. $41 \mathrm{v}$. 
El primer prototipo es un carro de guerra con aspecto de torre de madera -incastellatum-, que se desplaza sobre cuatro ruedas. Su sistema de propulsión se basa en el giro de dos manivelas accionadas por los hombres situados en el interior del carro, que ponen en marcha sendos sistemas de engranajes -uno en cada eje- que transmiten el movimiento a las ruedas del carro. Para que esta transmisión sea posible las ruedas y los engranajes están dentados. Un mecanismo de dirección en la parte delantera permite el control desde el interior (Fig. 61) ${ }^{63}$.

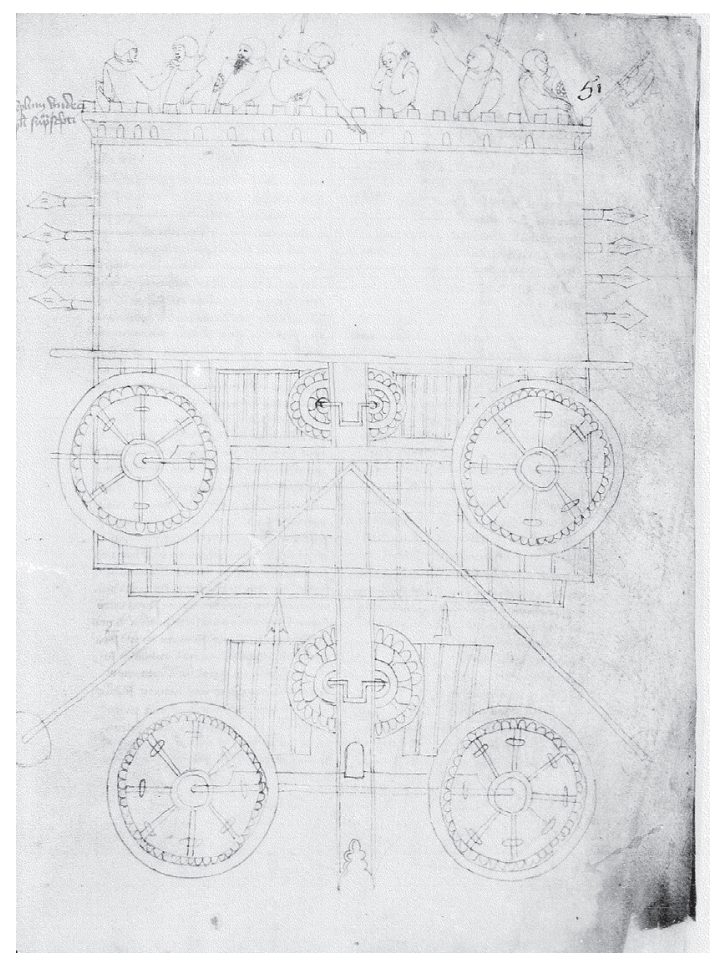

Fig. 61. Carro de guerra. Thexaurus, f. 51r.

El segundo está inspirado en el mecanismo de funcionamiento de los molinos de viento, razón por la cual para su construcción Guido da Vigevano apela a la habilidad del magistre molendinorum et maxime de ventum. Su originalidad radica en la aplicación de aquel mecanismo para la puesta en movimiento de una máquina, cuyo resultado sería un carro de guerra propulsado por el viento: el giro de unas aspas situadas en el exterior y unidas mediante un eje a una rueda dentada colocada en la parte superior del ingenio, transmitiría el movimiento hacia las ruedas delanteras del carro gracias a un engranaje de piñones y ruedas dentadas.

\footnotetext{
${ }^{63}$ Thexaurus, cap. XI, ff. 50r-50v.
} 
Si no hubiese viento, unas barras de madera colocadas en la rueda dentada central -la que transmite el movimiento a las ruedas delanteras del carro- permitiría accionarla manualmente, mientras que una manivela serviría para propulsar las ruedas traseras. También está dotado de un sistema de dirección manejable desde el interior (Fig. 62) 64 $^{2}$

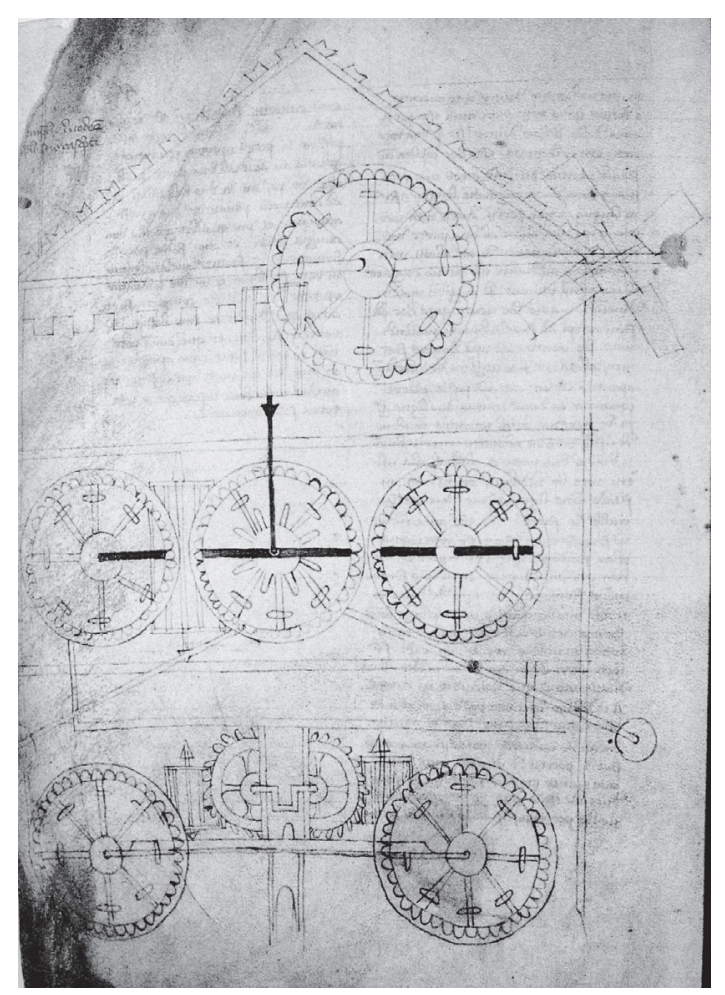

Fig. 62. Carro de guerra. Thexaurus, f. 52v.

No ofrece demasiados datos sobre su montaje, si bien de la descripción de ambos ingenios se infiere que serían desmontables, sus piezas transportables a caballo y su rápido ensamblaje no requeriría más de una noche o un día de trabajo. A juicio de Guido, con su utilización multa bona consequentur pro terra sancta conquirenda ${ }^{65}$.

La presencia de corrientes de agua que tenían que ser atravesadas por los expedicionarios podía dificultar las operaciones, de ahí que el autor ofreciese diversas soluciones tecnológicas para ayudar a superarlas o a navegar por ellas, propuestas

\footnotetext{
${ }^{64}$ Thexaurus, cap. XII, ff. 51v-52r.

65 Ibidem, 52r.
} 
que se integrarían en lo que podríamos denominar "máquinas o artilugios acuáticos". Para atravesar ríos diseña varios artefactos, empezando por un puente construido mediante la unión de piezas transportables a caballo, que puede montarse o plegarse en una hora. Siguiendo técnicas ya utilizadas en otros artificios, se forma con módulos de dos tablas que se clavan y se encolan. Estos módulos se unen entre sí mediante dos anchas cuerdas -en el dibujo parecen dos cinturones terminados en broches- que los ensartan a través de unos agujeros practicados en los dos extremos exteriores de las tablas, mientras que por la superficie otras dos cuerdas más finas atraviesan unas anillas fijadas a las tablas, otorgándole mayor estabilidad. Un parapeto construido con barras de hierro contribuye a la seguridad del paso, y un ancla lo fija al cauce con la ayuda de una barca (Fig. 63) ${ }^{66}$.

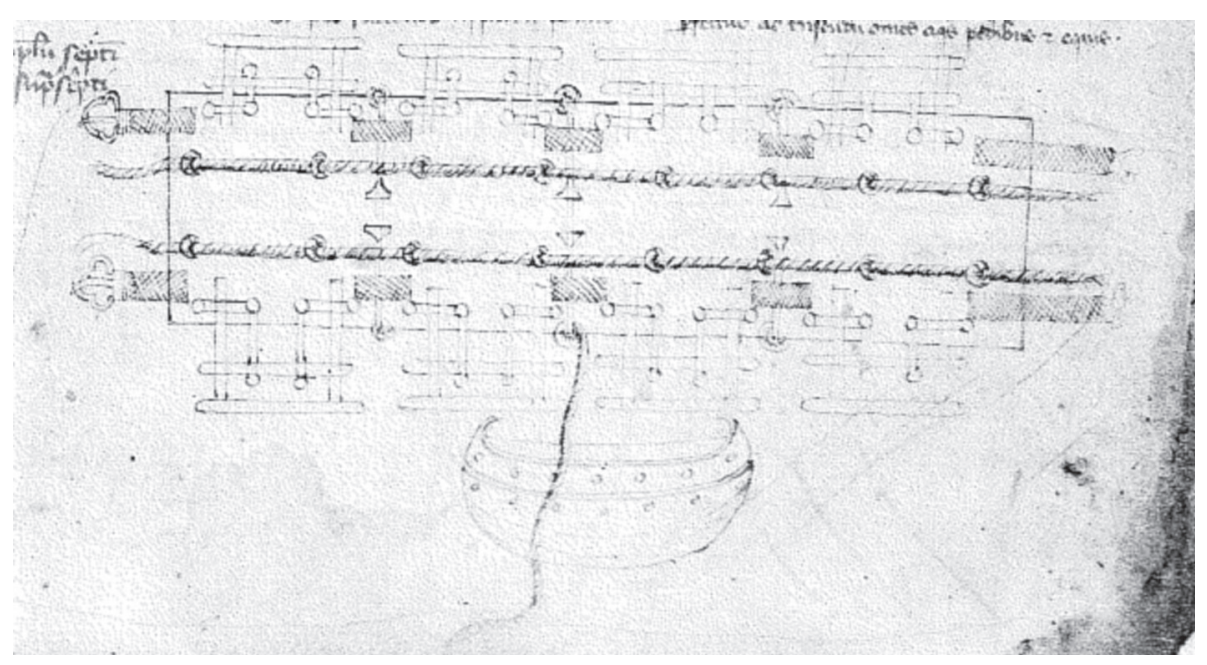

Fig. 63. Puente. Thexaurus, f. 48r.

Otros artilugios también ayudan en la travesía de ríos: se trata de dos modelos de flotadores, uno adaptado al caballo con su jinete, el otro al peón. El primero se fabrica con cuatro pieles y dos estacas que debían tener la longitud del caballo. Fijando con clavos las pieles a las estacas se construyen dos toneles o botes - una bota rotunda-, que deben tener un hueco para que el caballero pueda sacar las piernas y los estribos. Estos flotadores se fijan a la silla de montar mediante correas (Fig. 64) ${ }^{67}$.

\footnotetext{
${ }^{66}$ Thexaurus, cap. VII, f. 48r.

${ }^{67}$ Thexaurus, cap. IX, f. $49 \mathrm{v}$.
} 


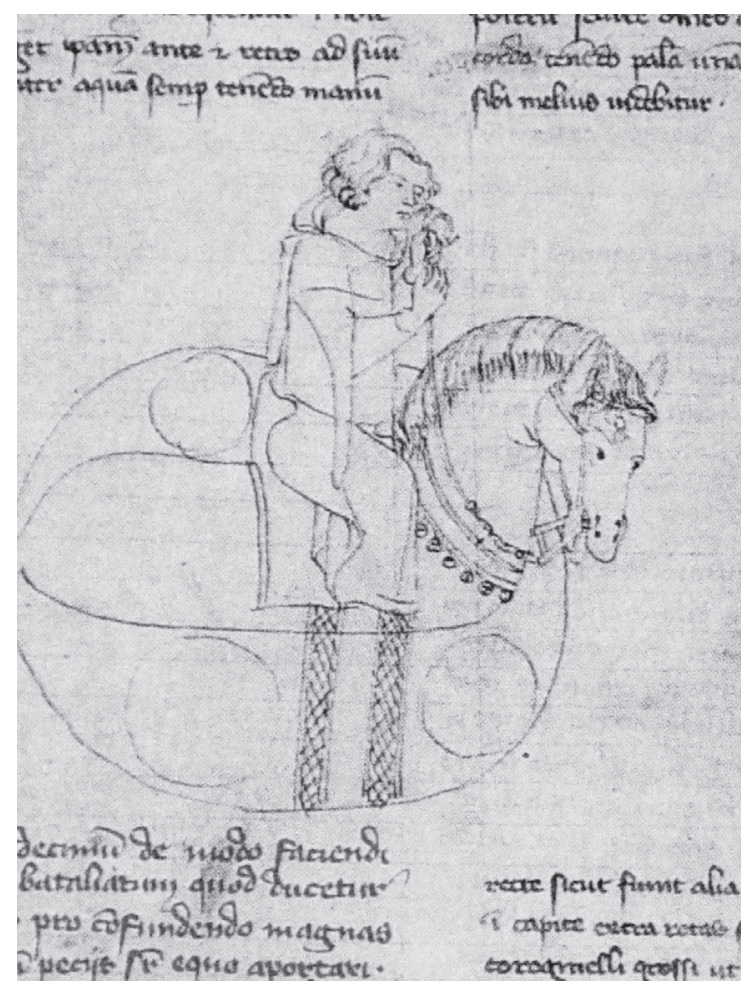

Fig. 64. Flotador. Thexaurus, f. 50r.

El flotador para peones se construye de la misma forma, si bien con una hendidura en la parte superior a modo de asiento y dos estribos para dar estabilidad al usuario, que además se fija al bote mediante un cinturón. Para dar seguridad a la travesía debía extenderse de una orilla a otra una cuerda gruesa a la que estarían cogidos los hombres y de la que se servirían para impulsarse. Se podía prescindir de esta última precaución si el bote se componía de tres barriles, puesto que entonces el peón, sentado en el situado en el centro, se valía de uno o dos remos (Fig. 65) ${ }^{68}$.

\footnotetext{
${ }^{68}$ Thexaurus, cap. X, ff. 50r-50v.
} 


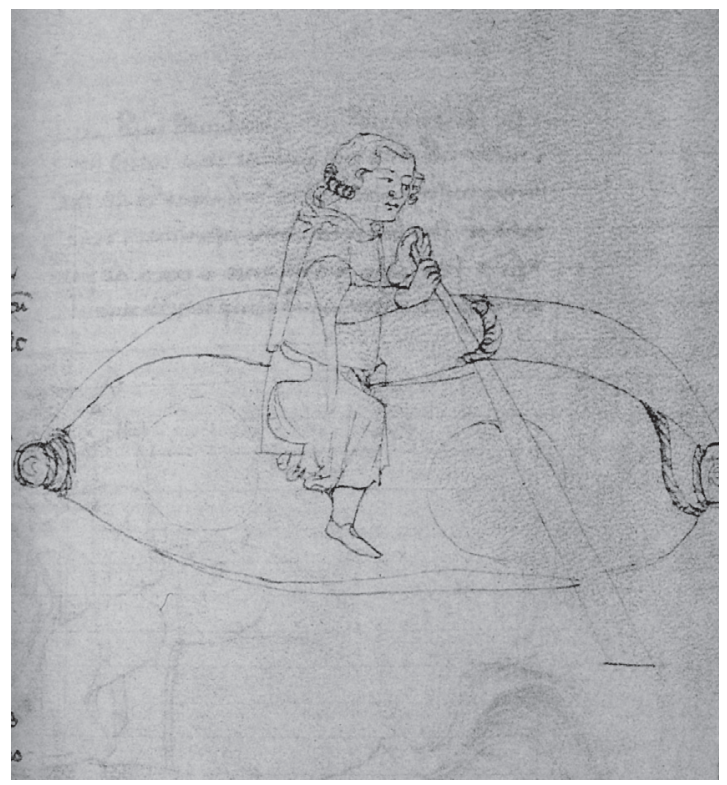

Fig. 65. Flotador. Thexaurus, f. 50v.

Para la navegación Guido da Vigevano propone la construcción dos tipos de barcos. El primero de ellos es el más singular: una nave plegable que se movía gracias a un sistema de manivelas y aspas. El texto detalla la forma de ensamblaje: el fondo se construye con tres tablones articulados, unidos mediante bisagras -plegables-, e impermeabilizados con cuero. Las paredes del barco también se fijaban al fondo con goznes e igualmente eran abatibles para facilitar su transporte a caballo. Siete costillas aseguran la firmeza interior de la embarcación y cuatro barriles amarrados en el exterior aseguraban su flotación. Su mecanismo de propulsión resultaba de todo punto original: a proa y a popa del barco, dos manivelas de hierro -cigüeñales -, manejados como los molinos de mano, se fijaban a sendos ejes de madera que a su vez transmitían el movimiento a cuatro aspas o ruedas hidráulicas que impulsaban la nave. Una vela y un timón facilitaban la travesía. Su virtualidad radicaba en la facilidad de su transporte - un caballo podría llevar un barco- y en la rapidez de su montaje -apenas se necesitaba una hora- (Fig. 66) ${ }^{69}$.

${ }^{69}$ Thexaurus, cap. VIII, ff. 48v.-49r. 


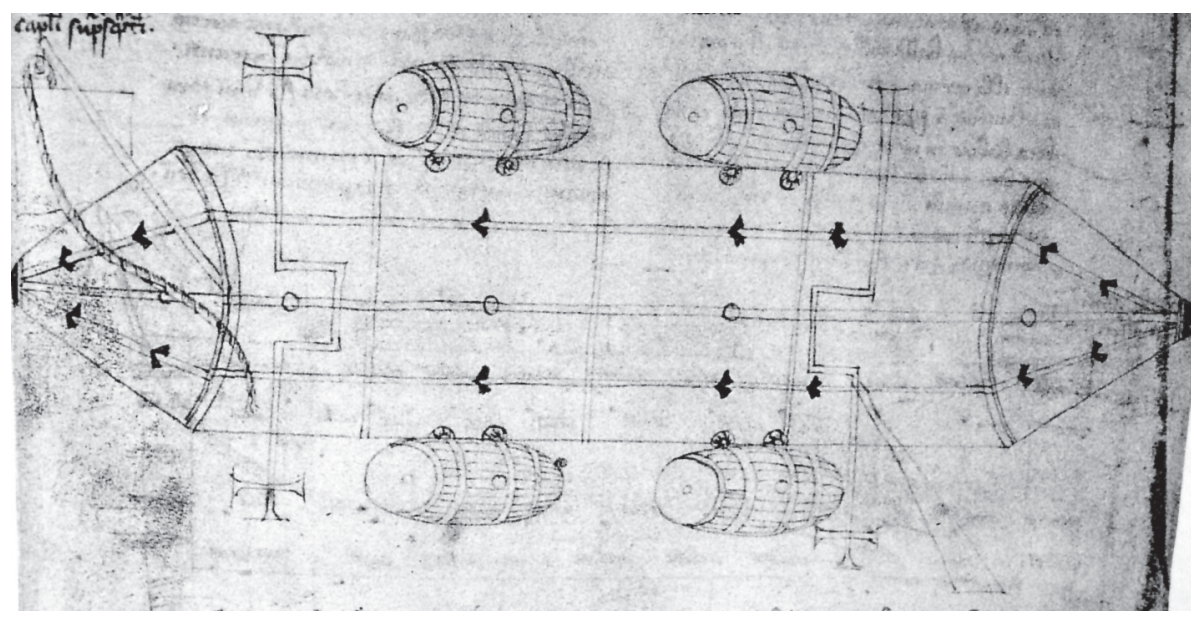

Fig. 66. Barco plegable propulsado por manivela. Thexaurus, f. 49r.

El segundo tipo de embarcación es un pontón construido con tablones de la misma manera que la rampa de asedio o que el puente ya presentados, pero soportado sobre barriles o toneles flotantes que a su vez descansan sobre dos postes articulados según el sistema ya comentado para otros artefactos. Parece diseñado para el transporte de caballos. Aunque el texto no lo indica, el dibujo deja claro que se mueve a vela (Fig. 67)

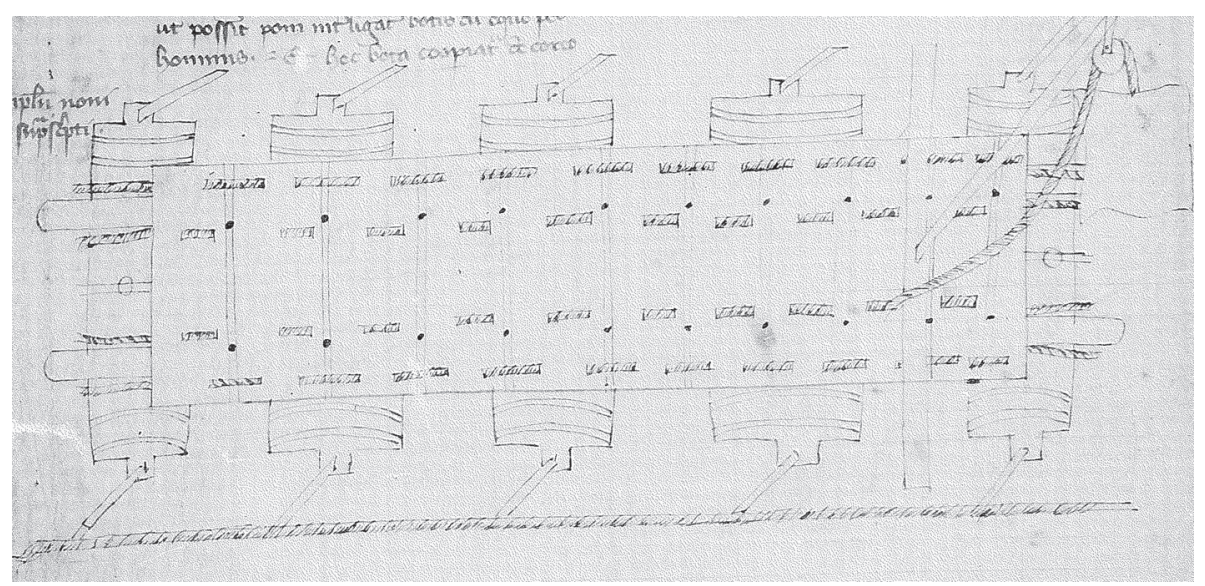

Fig. 67. Embarcación a vela. Thexaurus, f. 49v.

${ }^{70}$ Thexaurus, cap. VIII, f. 49r. 
En función de todo lo que hemos visto, no puede negarse que la obra de Guido da Vigevano representa un hito de la historia de la técnica en general y de la tecnología militar en particular, y no tanto porque sus aportaciones sirvieran para modificar la práctica bélica, cosa que no ocurrió, cuanto por el hecho de que contribuyó de manera definitiva a consolidar un género literario centrado en aquellas materias y en difundir el interés por las máquinas de guerra entre un público más amplio que el del estrecho círculo de los maestros. Desde luego la explicación de su éxito, comprobable cuando se observa su influencia entre los autores que siguieron su estela durante el siglo XV y hasta bien entrado el Renacimiento, no está en la eficacia de sus propuestas ni en la carga pragmática de sus soluciones, que después de todo tardarían siglos en demostrarse, sino en lo imaginativo de sus diseños. Y cabría recordar que, después de todo, para explicar el triunfo del hombre como inventor y el desarrollo de la tecnología moderna,

debe hablarse necesariamente de la necesidad de visualizar un objeto distante, del impulso de imaginar algo que aún no se ha conseguido, de la inclinación a buscar alguna forma práctica de convertir la visión en realidad. Incluso hoy, en el más técnico de los contextos, la innovación es un acto imaginativo ${ }^{71}$.

\section{BIBLIOGRAFÍA CITADA}

Altoé, Waldemiro; Ventorim, Eliane; Costa, Ricardo da (eds. y trads.), Raimundo Lúlio e as cruzadas), Río de Janeiro, Sétimo Selo, 2009.

Barrio Vega, Ma Felisa, Edición crítica y traducción del Epitoma Rei Militaris de Vegetius. Libros III y IV, a la luz de los manuscritos españoles y de los más antiguos testimonios europeos, Madrid, Editorial de la Universidad Complutense, 1982.

Basalla, George, La evolución de la tecnología, Barcelona, Crítica, 1991.

Bechmann, Roland, Villard de Honnecourt. Le pensée technique au XIII siècle et sa communication, París, Picard, 1993.

Bengedans, Johannes, Kriegskunst Und Kanonen/Artillery and the Art of War: Das Buchsenmeister- Und Kriegsbuch Des Johannes Bengedans, Olsen, Rikke Agnete; Blosen, Hans (eds.), Aarhus, Aarhus Universitetsforlag, 2006.

Berthelot, M., Pour l'histoire des arts mécaniques et de l'artillerie vers la fin du Moyen Age, "Annales de Chemie et de la Physique" 6a serie, 24 (1891), pp. 433-498.

Berthelot, M., Histoire des machines de guerre et des arts mécaniques au Moyen Age. Le livre d'un ingénieur militaire a la fin du XIVe siècle, "Annales de Chemie et de la Physique" XIX (1900), pp. 289-419.

Canestrini, Giovanni, Arte Militare Meccanica Medievale, Bolonia, Calderini, 1974.

Edgerton, Samuel Y., The Renaissance Development of Scientific Illustration, en Shirley, John William; Hoeniger, F. David (eds.), Science and the Arts in the Renaissance, Washington, Londres y Toronto, Folger Books, 1985, pp. 168-197.

Eiximenis, Francesc, Dotzen libre de regiment dels princeps e de comunitats appellat Crestià, Valencia, Lambert Palmart, 1484.

\footnotetext{
${ }^{71}$ A. Pacey, El laberinto, pp. 78-80.
} 
Galluzzi, Paolo, Art and Artifice in the Depiction of Renaissance Machines, en Lefèvre, Wolfgang; Renn, Jürgen; Schöpflin, Urs (eds.), The Power of Images in Early Modern Science, Basilea, Birkhäuser Verlag, 2003, pp. 47-68.

Gil de Roma, De Regimine Principum, Roma, Antonium Bladum, 1556.

Gille, Bertrand, Études sur les manuscrits d'ingenieurs du XVe siècle. Le manuscrit dit de la guerre hussite, "Techniques et civilisations" V (1956), pp. 77-86.

Gille, Bertrand, Les ingénieurs de la Renaissance, París, Hermann, 1964.

Gimpel, Jean, La revolución industrial en la Edad Media, Barcelona, Taurus, 1982.

Gruter von Werden, Konrad, De machinis et rebus mechanicis: Ein Maschinenbuch aud Italien für den König von Dänemark, 1393-1424, Lohrmann, Dietrich; Kranz, Horst; Alertz, Ulrich (eds.), Ciudad del Vaticano, Biblioteca Apostólica Vaticana, 2006, 2 vols.

Hall, A. Rupert, Guido's Texaurus, 1335, en Hall, Bert S.; West, Delno C. (eds.), On pre-modern technology and sciences: studies in honour of Lynn White, jr., Los Ángeles, Undena Publications, 1976, pp. 11-52.

Hall, Bert S., Giovanni de'Dondi and Guido da Vigevano: Notes Toward a Typology of Medieval Technological Writings, "Annals of the New York Academy of Sciences" 314 (octubre 1978), pp. 127-144.

Hall, Bert S. (ed.), The Technological Illustrations of the so-called Anonymous of the Hussite Wars: Codex latinus monacensis 197, part I, Wiesbaden, Reichert Verlag, 1979.

Hall, Bert S., Guido da Vigevano's Texaurus Regis Franciae, 1335, en Eamon, William (ed.), Studies on Medieval Fachliteratur, Bruselas, Omirel, 1982.

Hall, Bert S., Production et diffusion de certains traités de techniques au moyen âge, en Allard, Guy; Lusignan, Serge (eds.), Les arts mecaniques au moyen âge, Montréal, Bellarmin - París, J. Vrin, 1982, pp. 147-170.

Housley, Norman, The later crusades, 1274-1580: from Lyons to Alcazar, Nueva York, Oxford University Press, 1992.

Isidoro de Sevilla, Etimologías, Oroz Reta, José; Marcos Casquero, Manuel A. (eds.), Madrid, Editorial Católica, 1983.

Leng, Rainer, Ars belli. Deutsche taktische und kriegstechnische Bilderhandschriften und Traktate im 15. und 16. Jahrhundert, Reichert Verlag, Wiesbaden, 2002.

Leopold, Antony, How to Recover the Holy Land. The Crusade proposals of the late thirteenth and early fourteenth centurias, Aldershot, Ashgate, 2000.

Mariano Jacopo «Il Taccola», De rebus militaribus (De Machinis, 1449), Knobloch, Eberhard (ed.), Baden-Baden, V. Koerner, 1984.

Mcgee, David, The Origins of Early Modern Machine Design, en Lefèvre, Wolfgang (ed.), Picturing Machines, 1400-1700, Cambridge, The MIT Press, 2004.

Navareño Mateos, Antonio, El armamento y la poliorcética medievales en el Códice Latino 197 de Munich, "Norba-Arte" XII (1992), pp. 29-66.

Ostuni, Giustina (ed.), Le Macchine del Re. Il Texaurus Regis Francie di Guido da Vigevano. Trascrizione, traduzione e commento del codice lat. 11015 della Bibliothèque Nationale di Parigi, [Milán], Diakronia, 1993.

Pacey, Arnold, El laberinto del ingenio. Ideas e idealismo en el desarrollo de la tecnología, Barcelona, Gustavo Gili, 1980.

Popplow, Marcus, Militärtechnische Bildkataloge des Spätmittelalters, en Kortüm, Hans-Henning (ed.), Krieg im Mittelalter, Berlín, Akademie Verlag, 2001, pp. 251-268.

Quarg, Götz, Conrad Kyeser aus Eichstätt «Bellifortis», Düsseldorf, V.D.I. Verlag, 1967.

Reti, Ladislao, Francesco di Giorgio Martini's (1439-1501). Treatise on Engineering and Its Plagiarits, "Technology and Culture" 4 (1963), pp. 287-298. 
Sanuto Torsello, Marino, Liber secretorum fidelium crucis, en Bongars, Jacques (ed.), Gesta Dei per Francos, Hannover, Typis Wechelianis, 1611, vol. II, pp. 1-288.

Schein, Sylvia, Fidelis Crucis. The Papacy, the West, and the Recovery of the Holy Land, 1274-1314, Oxford, Clarendon Press, 1991.

Tyerman, J., Philip VI and the Recovery of the Holy Land, "English Historical Review" 100 (1985), pp. 25-52.

Valturio, Roberto, De re militari, Verona, 1483, (reimpresa en París, Apud Christianum Wechelum, 1534).

Vegecio, Compêndio da Arte Militar, João Gouveia Monteiro; José Eduardo Braga (eds.), Coimbra, Imprensa da Universidade de Coimbra, 2009.

Villard de Honnecourt, Cuaderno. Siglo XIII. A partir del manuscrito conservado en la Biblioteca Nacional de París (n. 19093), Erlande-Brandenburg, Alain; Pernoud, Regine; Gimpel, Jean; Bechmann, Roland (eds.), Madrid, Akal, 1991.

Villas Tinoco, Siro; Montiel Torres, Francisca, Historia, Ciencia y Tecnología, Málaga, Universidad de Málaga, 2000.

Villena, Leonardo, Bibliografía clásica de poliorcética y fortificación, "Castillos de España" 49 (1965), pp. 153-190.

Vitrubio, Los diez libros de Arquitectura, Madrid, Alianza, 1995.

White, Lynn, Tecnología en la Edad Media, en Kranzberg, Melvin; Purcell, Carroll W. (eds.), Historia de la Tecnología. La técnica en Occidente de la Prehistoria a 1900, Barcelona, Gustavo Gili, 1981, vol. I.

Wisman, Josette A., L'Epitoma rei militaris de Végèce et sa fortune au Moyen Age, "Le Moyen Age" 55 (1979), pp. 13-31.

Fecha de recepción del artículo: julio 2011

Fecha de aceptación y versión final: octubre 2011 